\title{
دعم السياسة المالية للنمو
}

الاحتوائى

دكتور

حسام عبدالعال عبدالعال شعبان

مدرس الإقتصاد السياسي والمالية العامة

كلية الحقوق - جامعة عين شمس الحس 



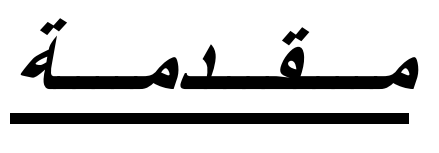

شرعت الحكومة المصرية مؤخر ا في تبني خطة إصلاح اقتصادية

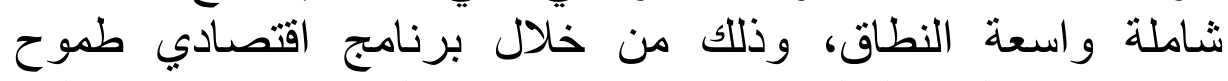

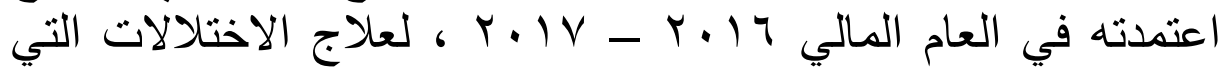

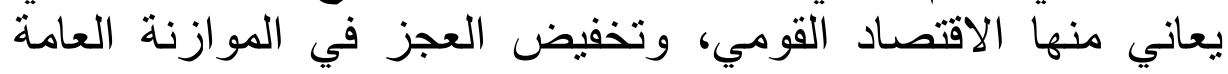

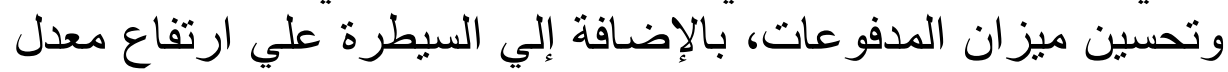

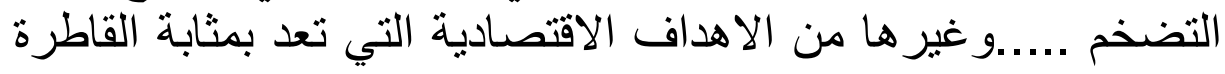
نحو نمو شامل ومستدام واحتو ائي.

وتطبيقا لذلك اتخذت الحكومة عدة قرارت هامة وجرئائة، تطبيقا

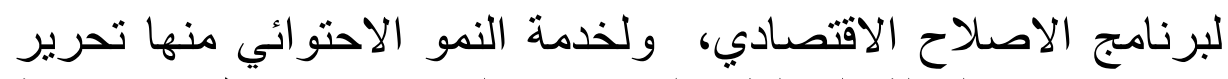

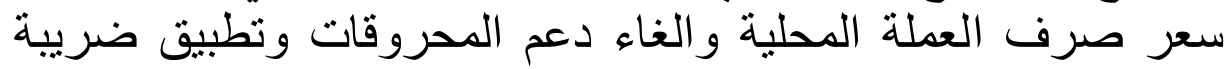

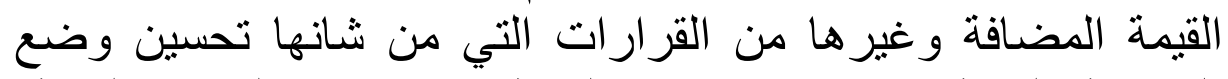

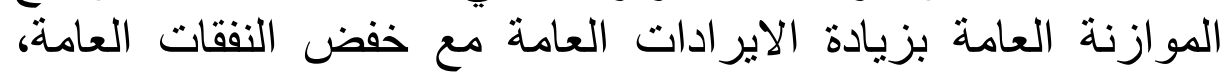

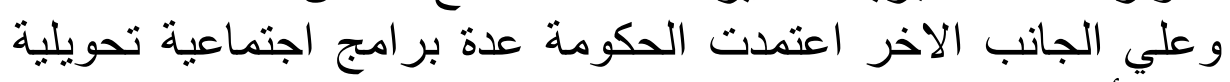

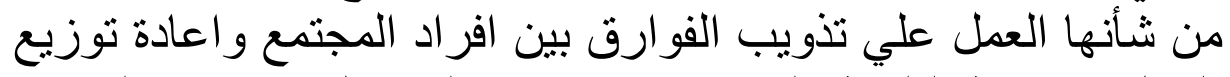

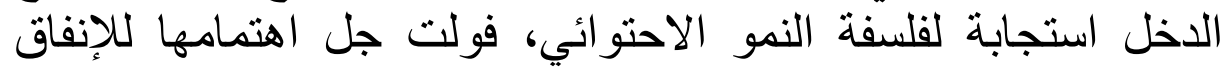
على الصحة و التعليم و التحويلات الاجتهية الاجتياعية.

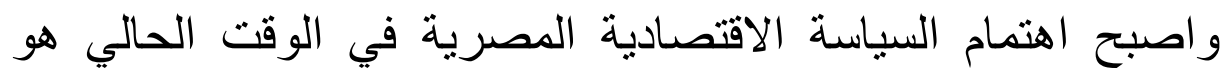

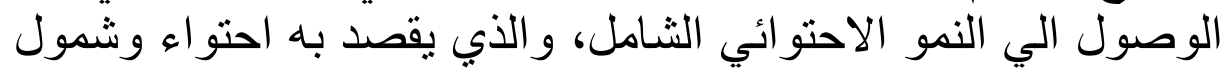

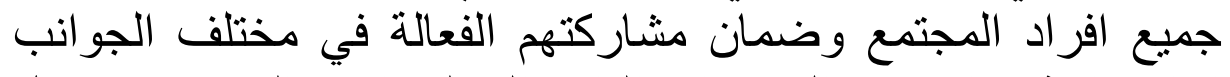

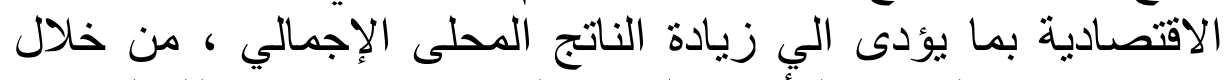

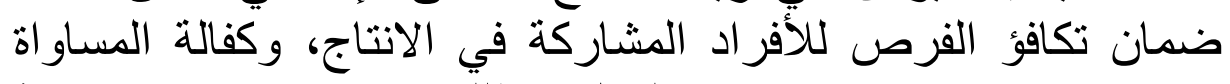

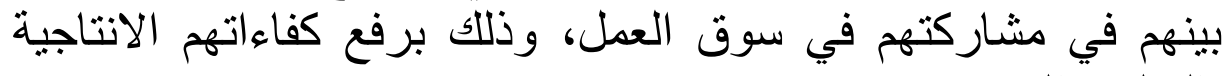

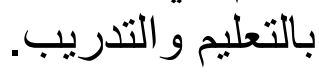
أهمية البحث

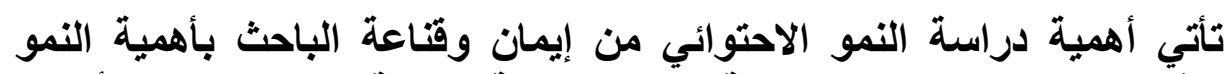
الاقتصادي الإحتوائي ، وحتمية دعم العياسة المالية بما تملكه من أدوات النيات 
هامة، تستطيع توجيه مختلف أوجه الأنشطة الاقتصادية بما يعود بالنفع

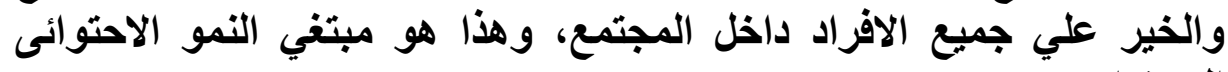
المستثام.

\section{مشكية البحث}

تكمن مشكلة دراسة النمو الاحتوائى فى حداثته النسبية وصعوبة النية

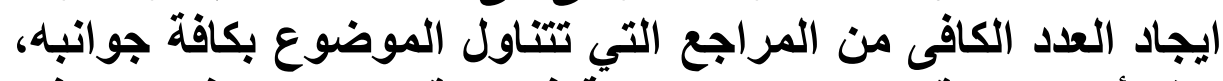

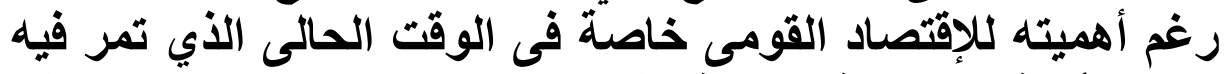

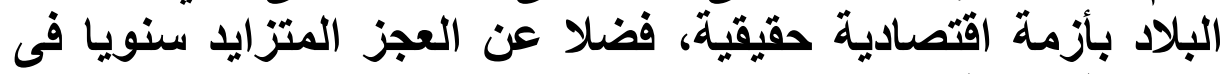
الموازنة العامة.

\section{أهداف البحث}

يهدف البحث إلى توضيح النقاط التالية:-

ا ـ التعرف على مفهوم وأهمية النمو الاحتوائي. Y - معرفة العوائق والتحديات الحقيقية للنمو الاحتوائي. بـ التعرف علي أدوات السياسة المالية الداعمة للنمو الاحتوائى. ع- معرفة كيفية التأثير الإيجابى للسياسة المالية على النمو

$$
\text { الإحتوائى. }
$$

\section{منهج البحث و الدراسة}

اعتمد الباحث على المنهج الوصفى التحليلى لمناسبته لطبيعة

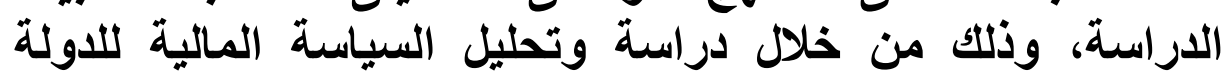

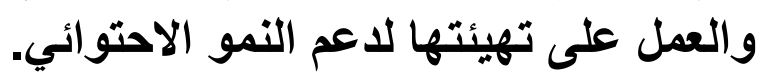

خطة البحث: :- 


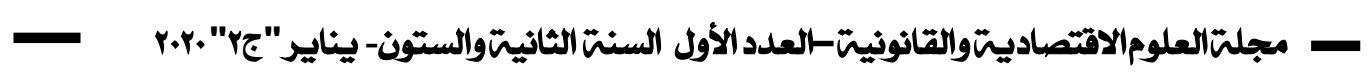

للألمام بموضوع البحث " دعم السياسة المالية للنمو الاحتوائى"

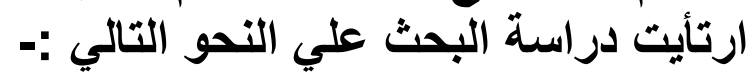

تمهيد

المبحث الأول : ماهية النمو الاحتوائى واهميته.

المبحث الثاني: معوقات (تحديات) النمو الاحتوائى.

المبحث الثالث: كيفية دعم السياسة المالية للنمو الاحتوائى.

الخاتمة

التوصيات

الفهرس 


\section{0}

تعانى معظم الدول النامية، لاسيما مصر، من تحدي تعزيز النمو الاحتوائي في ظل الحيز المالي المتاح والمحدود نسبيا ، لذا يتعين زيادة الظبط المالى لضمان إستمرارية دعم وتحمل المالية العامة للنمو الإحتوائى، الأمر الأى يحتم على متخذى القرار إعتماد مزيجا من الإجراعات والتذابير التي تعمل علي خفض النفقات العامة وزيادة الإيرادات.

ولضمان أن يكون التصحيح المالي داعما للنمو المستمر والإحتوائى يتعين توسيع القاعدة الضريبية والحد من الإعفاعات الضريبية مع وضع هيكل ضريبى أكثر تصاعدية بالإضافة إلى ضرورة تنويع قاعدة الإيرادات، كما ينبغى علي صعيد الإففاق العام إعادة التوازن بين عناصر الإنفاق نحو الاستثمار الرأسمالي المعزز للنمو والعالي الجودة، مع دعم الإنفاق الاجتماعي الموجه بلدةة إلى المستحقين.

ومن الجدير بالذكر أن عملية التصحيح المالى التي يتوقف علي فاعليتها زيادة النمو المستمر والإحتوائى، تعتمد في نجاحها علي جودة وإستمرارية الإجراءات والتدابير المالية المتخذة من قبل صانعي القرار'. فالعبرة ليست بحجم الإنفاق العام وإنما بجودته، بمعني توجيه الأولوية في النفقات العامة إلي الصحة والتعليم والبنية الأساسية بما يتشق وأهداف النمو الاحتوائي والمستمر. فالعبرة ليست بحجم الإنفاق العام وإنما بجودته، بمعني توجيه الأولوية في النفقات العامة إلي الصحة والتعليم والبنية الأساسية بما يتسث وأهداف النمو الإحتوائى والمستمر. 
لذا يحمد للحكومة المصرية الرشيدة إتجاهها في الأونة الأخيرة نحو تخفيض النفقات الجارية الذى بدا واضحا جليا فى مجال الدعم وفواتير وأجور القطاع العام بصفة عامة، ولكن يجب لكي يكتمل التصحيح المالى التركيز على زيادة

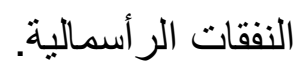

وأنوه هنا إلي خطورة المبالغة فى رفع سعر الفائده، حيث يؤدى إلي تدمير إيجابيات وفاعلية التصحيح المالى وستجد الدولة أنه بالرغم من التدابير المتخذه لزيادة الإير ادات وترشيد النفقات الجارية، إلا أن مؤشر الدين يظل مرتفعا ويكاد يستمر في التزايد نتيجة إبتلاع أسعار الفائدة المرتفعة ثمار التصحيح المالي. كما أن المبالغة في الإعفاءات الضريبية خاصة الإعفاءات المحفزة للشركات

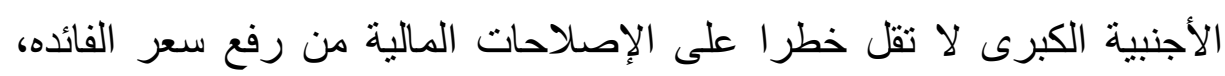
حيث أن المبالغة في إعفاء تلك الشركات ضريبيا سيؤدى إلي تمبيز المستهلكين الأغنياء على حساب الفقر اء، و هو ما بطعن النمو الإحتو ائى والمستمر في مقتل، إعلى ولعل الأفضل والاكثر دعما للنمو الإحتوائى من الإعفاءات الضريبية وتخفيض الإنى

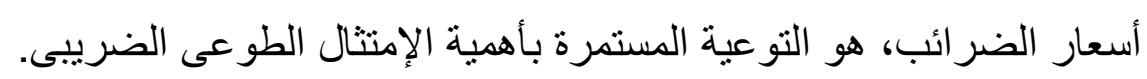

ولكن يجب التنبيه على أن التشريع الضريبى المصرى لازال بحاجة ماسة إلى

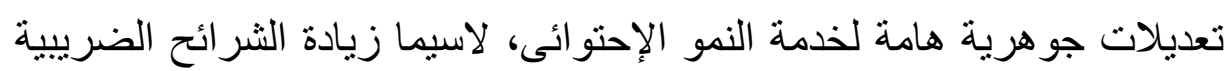
بما يضمن الإحتو اء الحقيقى لأصحاب الدخول المتدنية من قبل أصحاب الاخول المرتفعة، بالإضافة إلى العمل على زيادة مساهمة الثركات التجارية الكبرى.

ولا يفوتنى أن أسلط الضوء على أهمية خفض الدعم النفطى في تعزيز النمو الإحتو ائى والمستمر، و الذى يؤدى الى تقوية وصلابة المالية العامة بما يمكنها

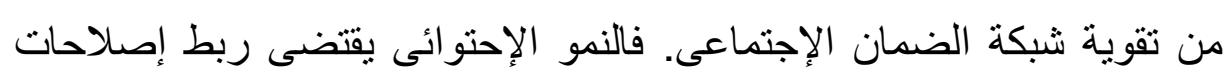


دعم الوقود بتقوية شبكة الأمان الإجتماعى بما يضمن وصول الدعم للمستحقين فقط ، من أجل تعزيز عدالة الإصلاح ودعم النمو الإحتو ائى والمستمر.

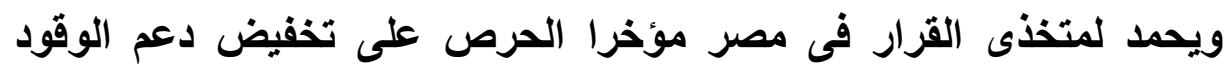

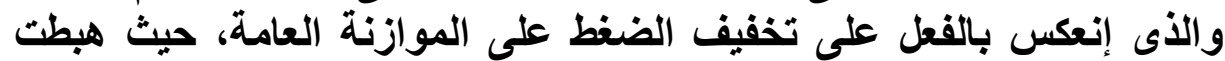

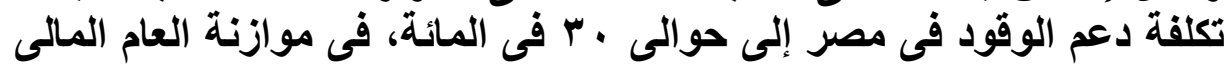
$r \cdot r \cdot-r \cdot 19$

وجدير بالملاحظة أنه بالفعل تم ربط دعم الوقود بتقوية شبكة الضمان

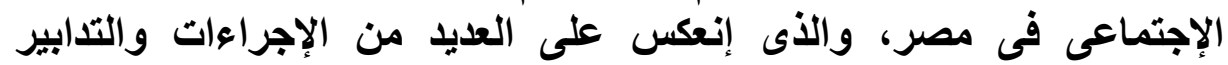

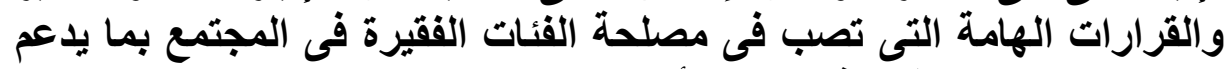

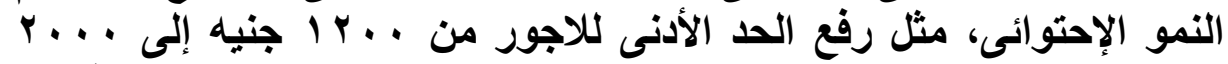

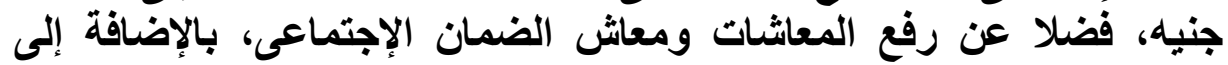

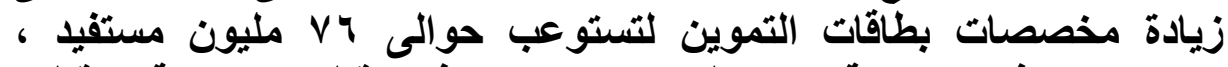

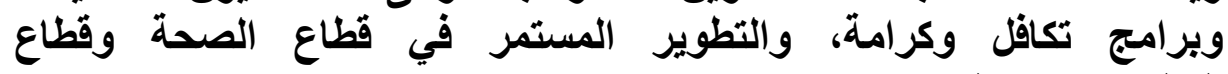
التعليم............الخ. ويرل.

و لا يفوتنى أن اثنير إلى أهمية الثفافية والمتابعة و الرقابة المستمرة للمالية العامة

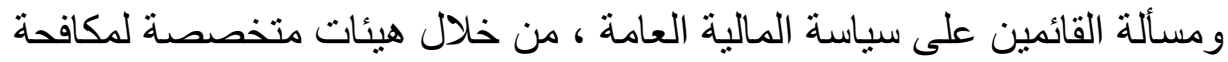

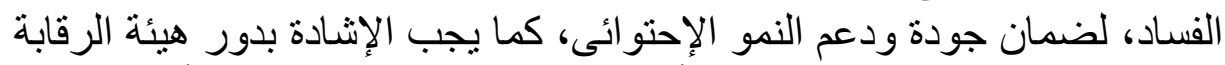

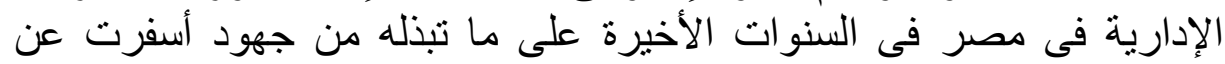

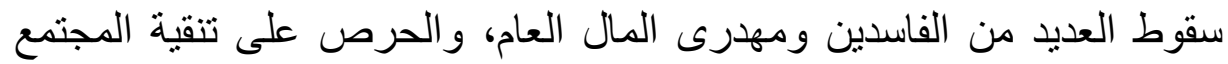

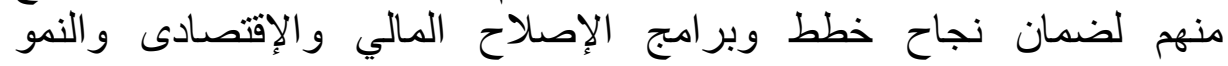
الإحتو ائى.

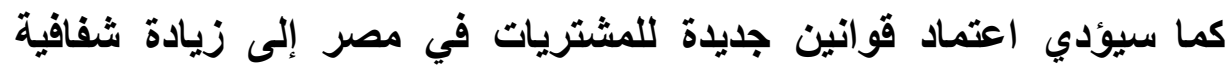

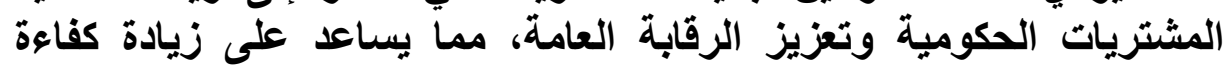

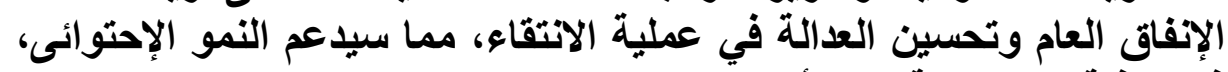

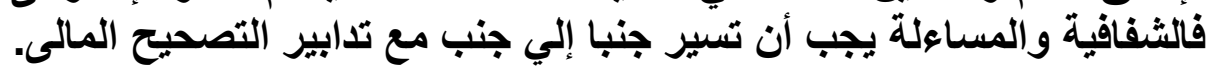

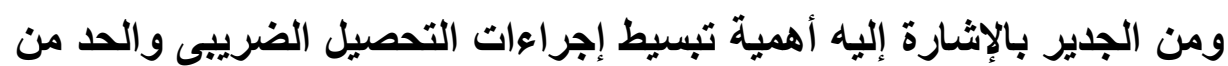

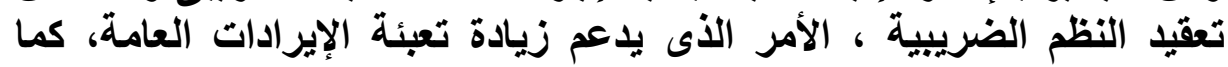

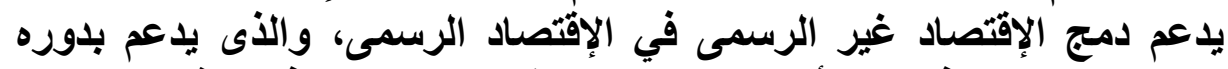

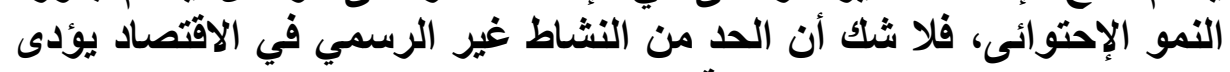

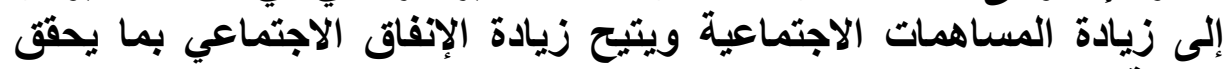
العدالة والنمو المستمر. 
وبشكل عام، يجب أن تسترشد جهود التصحيح المالي بأطر قوية للمالية العامة

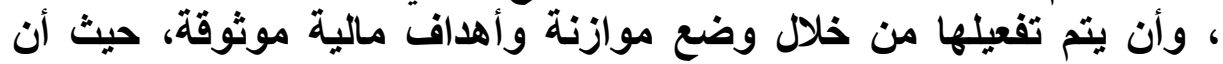

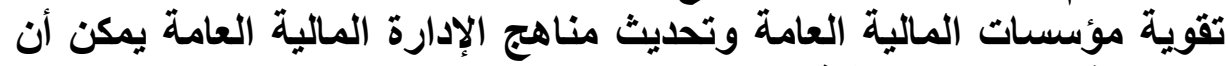

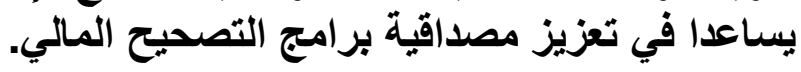

\section{المبحـث الأول}

\section{ماهية النمو الاحتو ائحى واهمبته}

يقصد بالنمو الاحتوائي "النمو المستدام علي مدار سنوات، والأي يرتكز علي

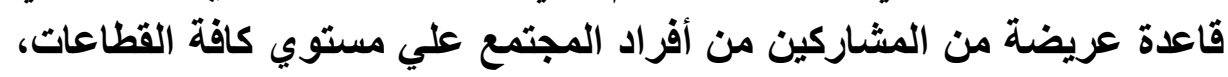

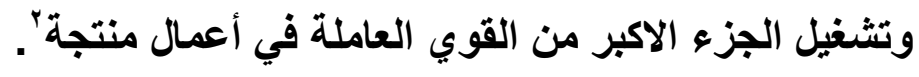

ولكي يوصف النمو بأنه احتوائي ، فينبغي ان تتوافر في النمو ثلاثة شروط

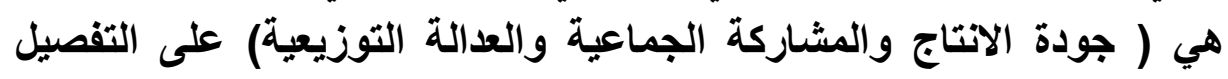
التالي:- (التي

1- جودة الاتتاج:- ويقصد بها رفع كفاءة الافراد المشاركين في العملية

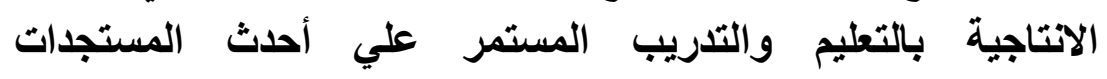

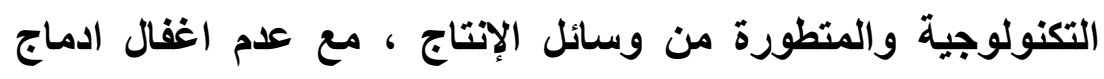

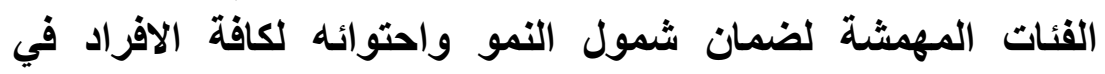

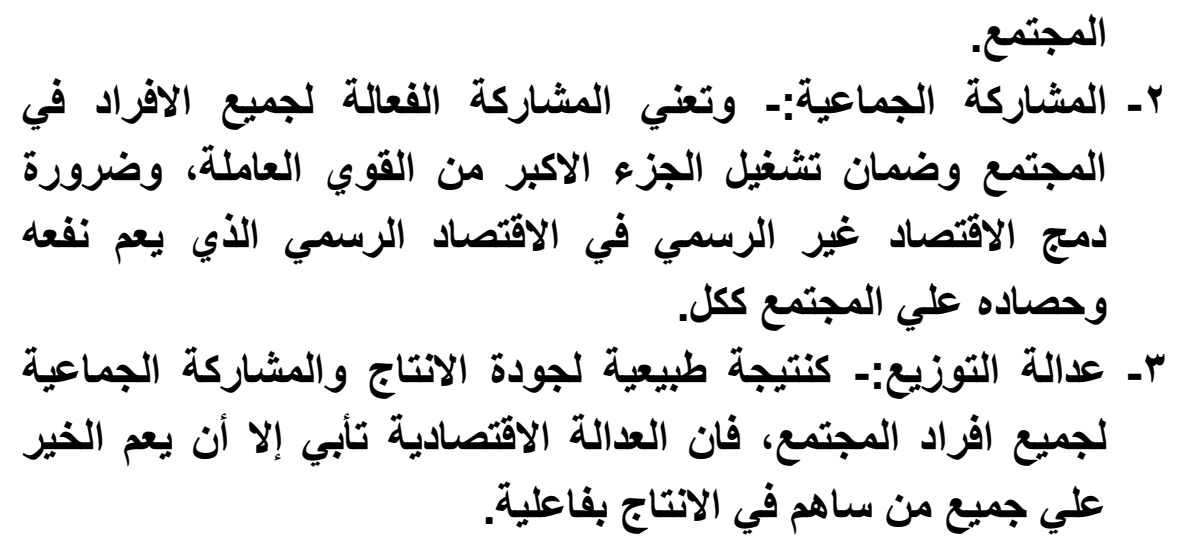

2 Dania Rodrik: "Growth Diagnostics" with R.Hausmann \& Andres Velasco in: J. Stiglitz \& N.Serra, eds, The Washington consensus Reconsidered : Towards a New Global Governance, Oxford University Press, New York, 2018. 
ولكن توجد مجموعة من العوائق والتحديات التي تمثل حجر عثرة حقيقية أمام النمو الاحتوائي، يمكن تلخيص هذه مذه العوائق في النقاط التالية:-

1- تهالك البنية الاساسية في أغلب القطاعات كالتعليم والصحة والنقل

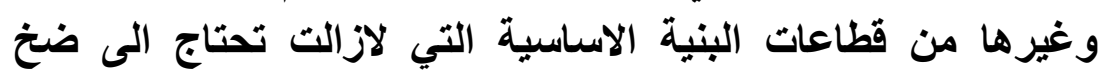

استثمارات كثيرة للنهوض فئهات بهات

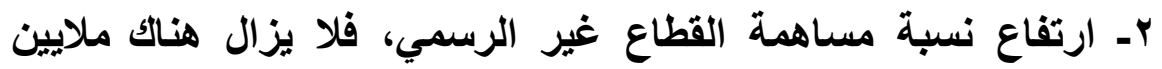

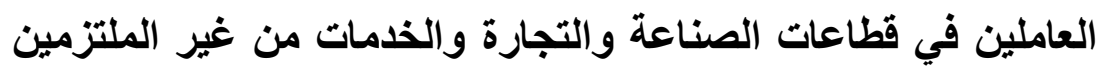

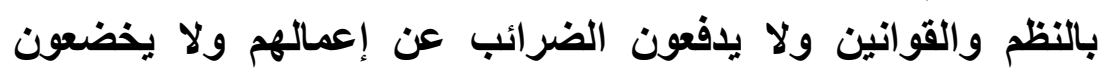
ل للأجهزة الرقابية المختلفة.

وتتضمن أهم مكونات الاقتصاد غير الرسمي، وفقا لاربة الرة أعدها اتحاد

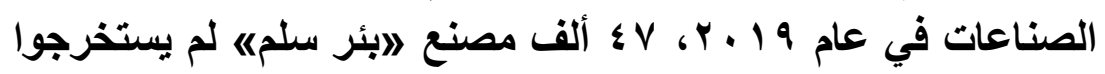

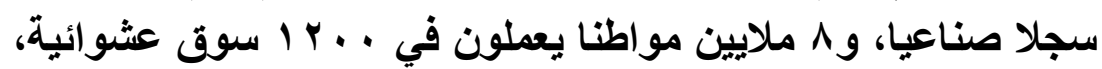
بالإضافة للباعة الجائلين ووجود عقارات غير مسائ مواتلة تقدر قيمتها

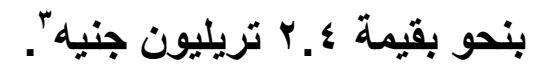
r- زيادة نسبة السكان المستمرة والتي تعد مشكلة حقئة حقيقية وليست

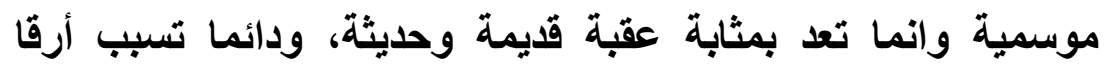

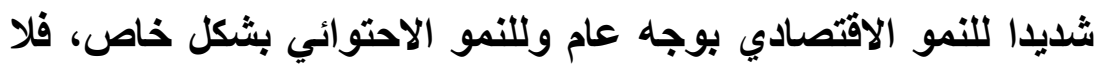

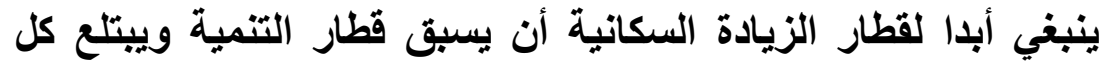

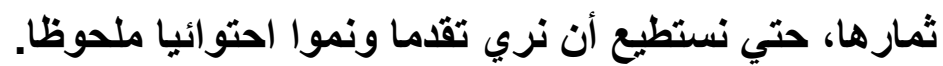

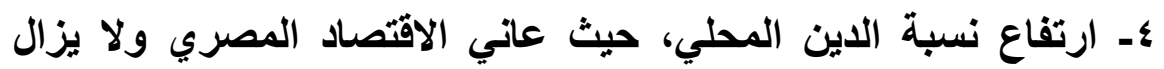

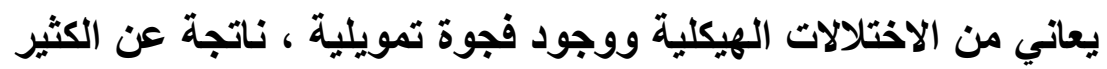

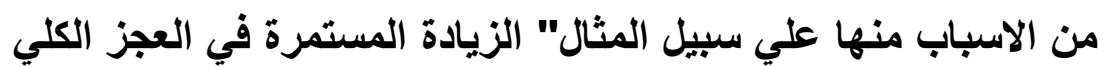

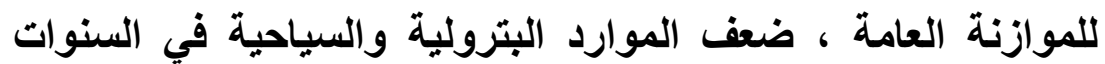

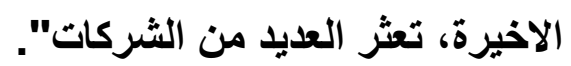

والكارثة الاقتصادية الكبرى أن الحكومة المصرية اتجهت أمام هذه الاختلالات والفجوة التضخمية إلي الاقتراض الإخلي والاقتراض الخارجي والتمويل

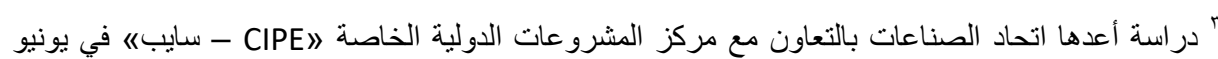

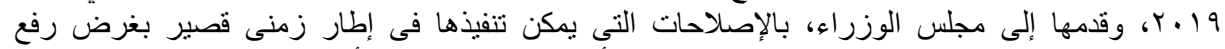

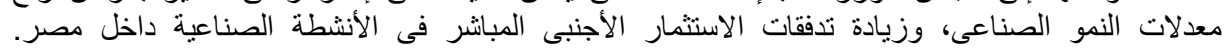
https://economyplusme.com/9691/ 
الضريبي والاصدار النقدي، وهي حزمة وسائل تمويلية تضخمية ، وتؤدي إلي

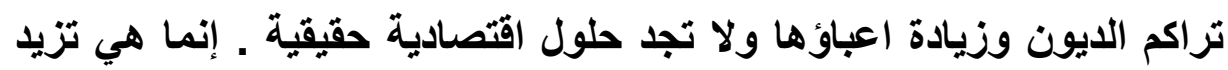
تراكم الديون وتورثئه لجيل بعد جيل.

وتوجد مجموعة من العوامل التي دفعت الاقتصاد المصري للاسف إلي الإفراط

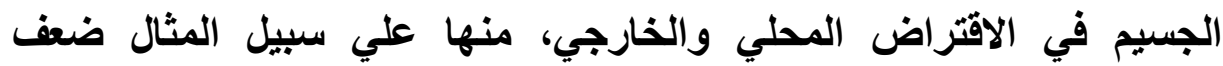

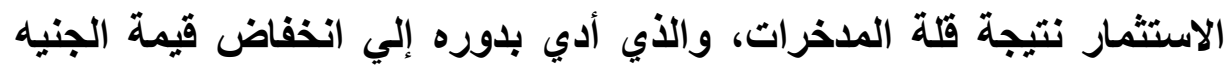

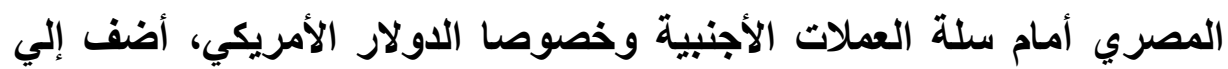

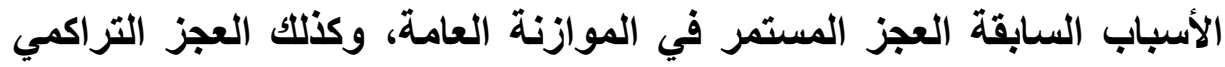

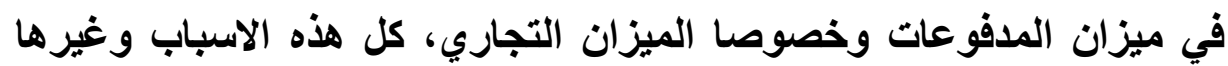

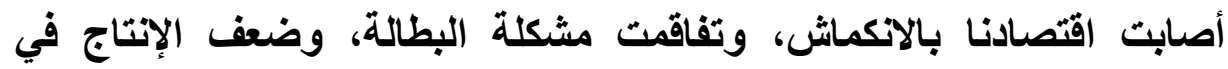

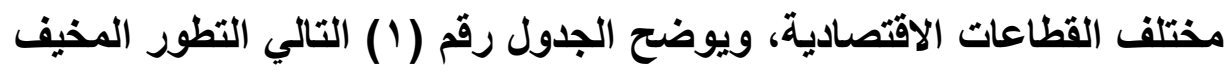

لحجم الاين المحلى.

\section{جدول رقم (1)}

تطور الاين المصري المحلى من بداية عام

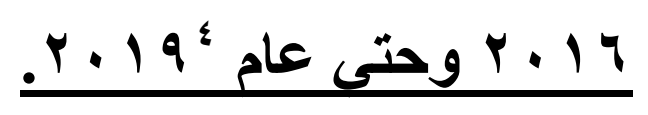

هـالقيمة بالمليون جنيه

\begin{tabular}{|c|c|c|c|c|}
\hline $\begin{array}{l}\text { يونيه } \\
\text { r. } 19\end{array}$ & يونيه 11 | ب & يونيه V ا ب ا & דارس & شهور البحث \\
\hline $11170 \wedge r$ & IOYVRVA & ITHAITV & $1.19 r V$ & إجمالي الدين \\
\hline
\end{tabular}

؛ تم إعداد الجدول الإسترشادي بواسطة الباحث إعتمادا علي بيانات البنك المركزي. 


\section{ولنا من خلال الجدول رقم (1) الملاحظات الأتية:-}

1 ـ يلاحظ أولا الزيادة المستمرة في حجم الدين العام سنة تلو الأخرى.

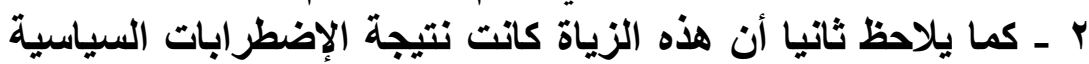

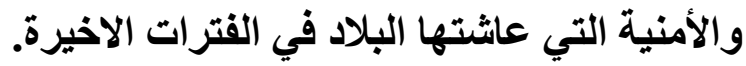

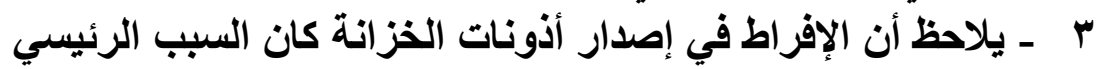
في ارتفاع حجم الدين العام المحلي.

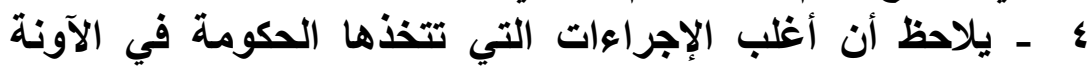
الأخيرة مجرد حلول تسكينيه مؤقتة.

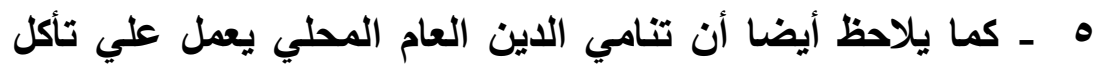

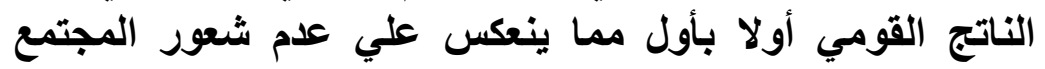

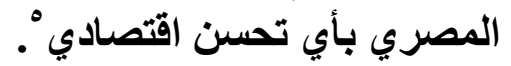

\section{المبحث الثناتي}

\section{معوقات (تحديات) النمو الاحتوائى}

السؤال الأى يطرح نفسه، ماهى العوائق التى تحول دون وصول مصر إلى الى التى

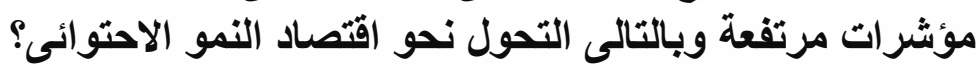

توجد مجموعة من العوامل التى تمثل تحديا حقيقيا للنمو الاقتصادى بصفة

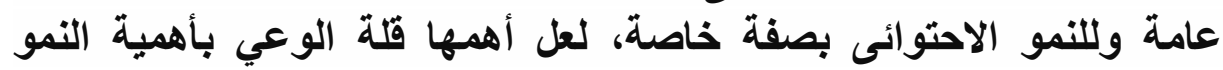

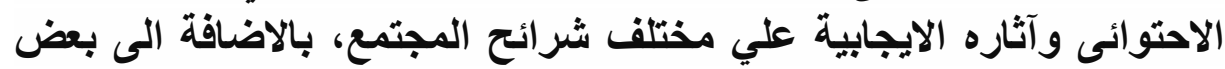
المعوقات الادارية والاقتصادية ، والتي التي نوضحها فى السطور التالية:-

\section{1 - تراجع مستويات التعليم وقلة الوعى بأهمية النمو الاحتوائحي:}

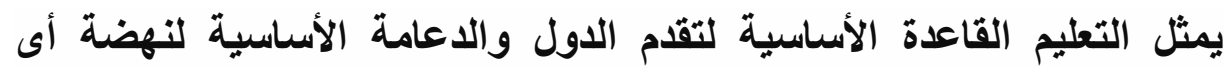

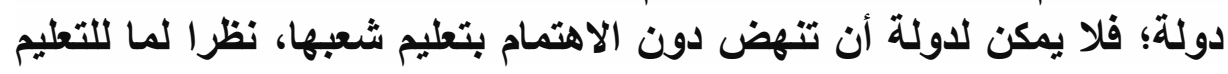

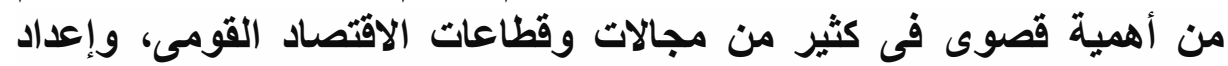

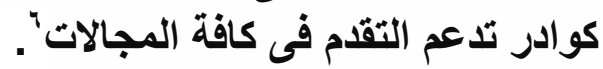

• مجلس الوزراء ، مركز المعلومات ودعم اتخاذ القرار ، الدين العام المحلي ومؤشر الاقتدار المالي العام

` للمزيد من التفصيل عن أهمية التعليم، ودور الجامعات فى بناء اقتصاد المعرفة، انظر. 
وللأسف يعانى التعليم فى مصر من مثكلات عديدة ، أهمها نقص الامكانات

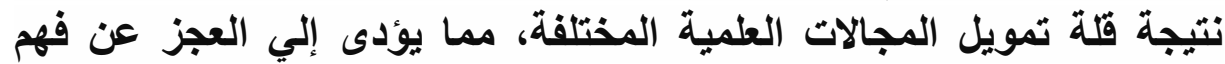

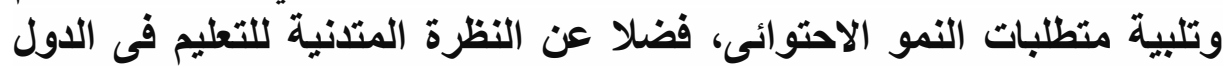

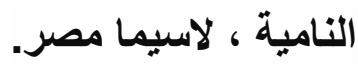

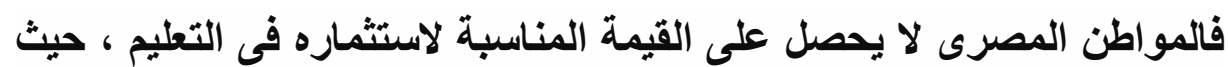

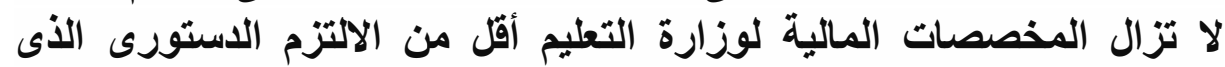

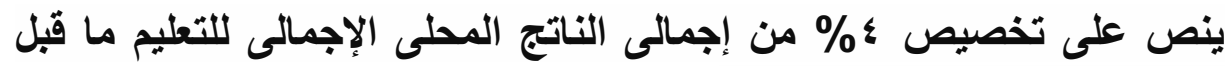

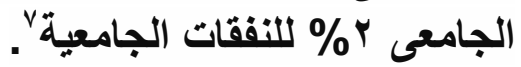

جدير بالأكر أن التقرير الأى أعدته الوكالة المركزية المصرية للتعبئة

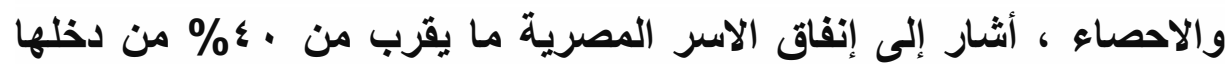

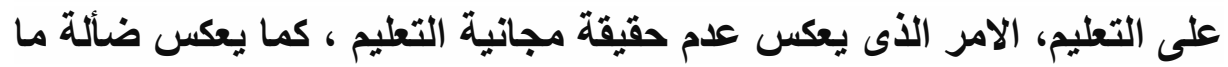

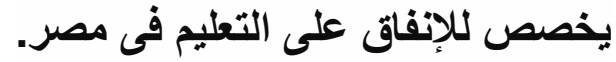

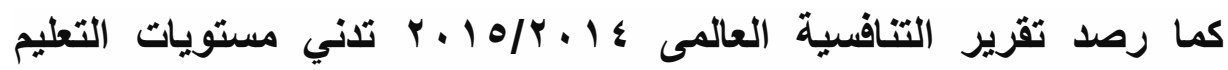

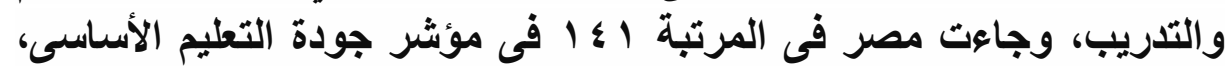

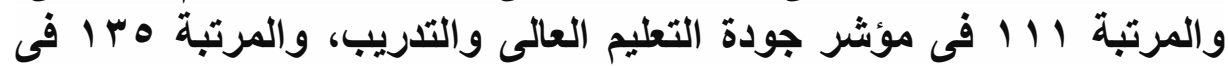

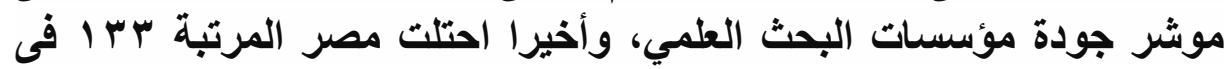

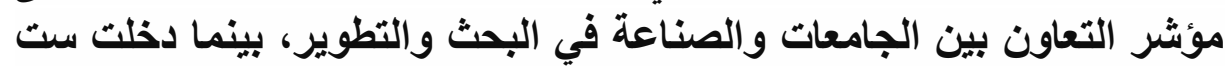

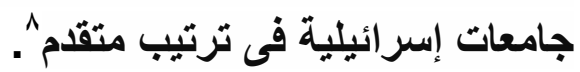

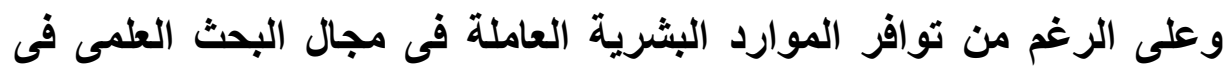

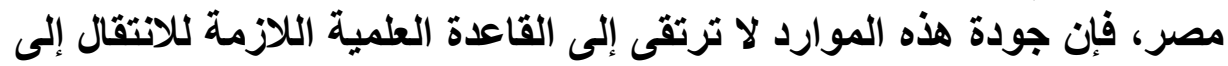

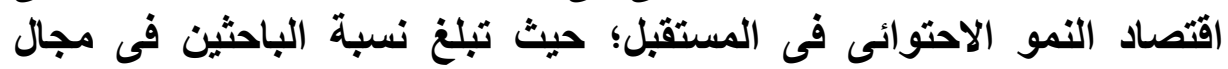

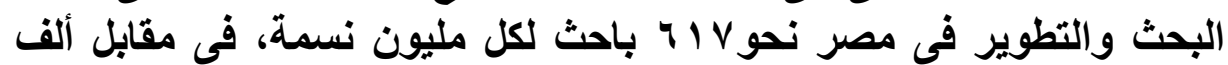

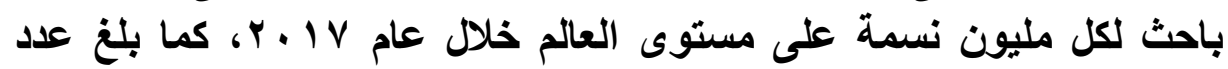

Timothy Hogan, An Overview of The Knowledge Economy, With A Focus on Arizona, Ph.D, School of Business, Arizona State University, August 2011, pp. 9,10.

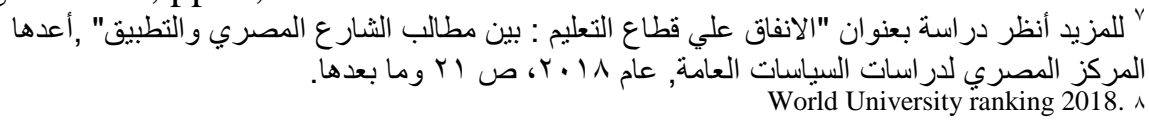




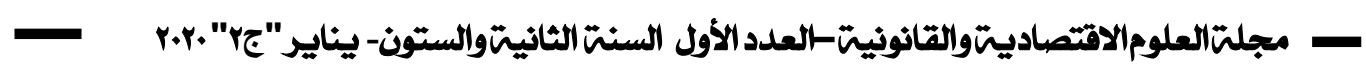

براعات الاختراع التى أصدرها مكتب براءات الاختراع المصرى بـ بـ بـ براءة

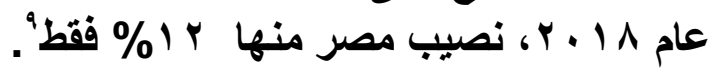

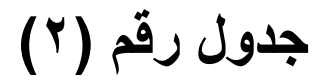

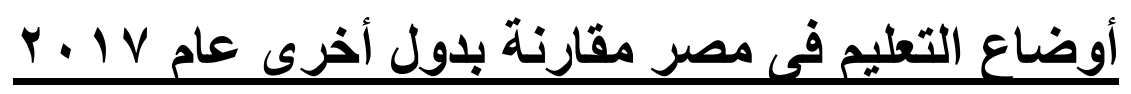

\begin{tabular}{|c|c|c|c|c|}
\hline الإنفاق على & \multicolumn{2}{|c|}{ عدد البراعات } & صادرات عالية & الدولة \\
\hline والتطوير & غير مقيمين & مقيمين & بالمليون دولار & \\
\hline$\cdot, Y 1$ & 7.0 & 1740 & 974 & مصر \\
\hline 1,1 & $r V \cdot O$ & $r \cdots$ & AIYY & البرازيل \\
\hline Y & $|\mu| \Lambda .0$ & $\begin{array}{r}\text { rAYq } \\
q\end{array}$ & q Y^० & كوريا \\
\hline$\cdot, 94$ & AYI & $007 Y$ & $1 \varepsilon Y$. & جنوب إفريقيا \\
\hline$\cdot, \wedge 0$ & Yo00 & $1 V V$ & $|V| \varepsilon$ & تركيا \\
\hline
\end{tabular}

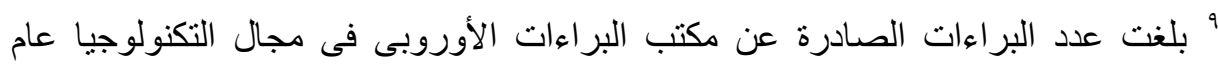

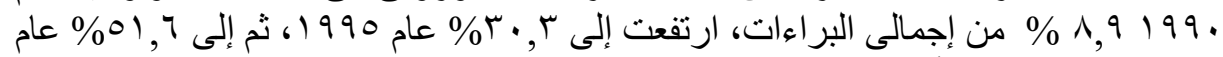

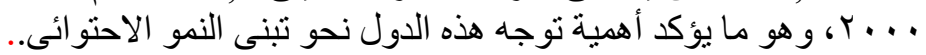
Zopp`e A, Patent activities in the EU: towards high tech patenting 1990 to 2000, Statistics in Focus, Science and Technology, No. 1, Luxembourg: Eurostat, 2002. 


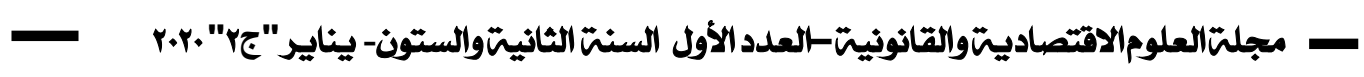

\begin{tabular}{|c|c|c|c|c|}
\hline$r, \wedge r$ & $\varepsilon V \cdot \varepsilon V$ & $\begin{array}{r}1 Y 19 \\
1\end{array}$ & $10 \wedge 0 \cdot V$ & ألمانيا \\
\hline $1, \wedge r$ & $10 \leqslant 9$. & $7 \leqslant r q$ & $09 \leqslant \varepsilon V$ & بريطانيا \\
\hline$r, v q$ & $r \& 19 V V$ & $\begin{array}{c}r \leqslant \wedge \\
0 .\end{array}$ & $1 \leqslant 0 \leqslant 91$ & المتلايات \\
\hline
\end{tabular}

Source : World Development Indicators, 2017.

ويعكس الجدول رقم (Y) تلنى نسبة الإنفاق على البحث والتطوير فى مصر حيث لا تتعدى اY, ·\% من الناتج المحلى الإجمالى، بينما تنفق دول أخرى معلات مرتفعة على هذا القطاع بلغ أعلاها فى كوريا الجنوبية بمعدل الاجل צr \% من الناتج القومى. ويمثل ضعف العلاقة بين مراكز البحث والتطوير والجهات الإنتاجية عائقا أمام تطبيق الأبحاث، وبالتالى عدم وجود مردود للابتكار على الأنشطة الإنتاجية، واقتصار الأبحاث التى تقوم بها الجهات الإتتاجية على أبحاث السوق والمستهلكين وليس بحوث الإنتاج والتكنولوجيا، وكذلك يشكل عدم التعاون بين الجهات الأكاديمية والقطاعات الإنتاجية وضعف التمويل اللازم لنقل الأبحاث التطبيقية إلى السوق، إلى جانب ضعف القدرات القنية والتقنية للعاملين عائقاً للتحول إلى اقتصاد المعرفة، وتتجلى نتائج تلك العوائق فى ضعف الصناعات التكنولوجية وبالتالى ضعف الصادرات التكنولوجية بحيث لم

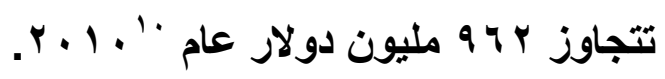

· للمزيد ، أنظر د/ آيات صلاح دكرورى، دور افتصاد المعرفة في تحديث الصناعة ، دراسة تحليلية بالتطبيق

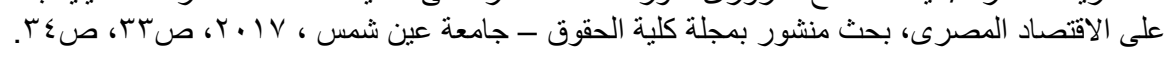




\section{r- ع عدم الاهتمام برأس المال البشرى}

العنصر البشري هو الثروة الحقيقية للمجتمع، لان العنصر البشري الكفع والمدرب والمعد إعداداً جيداً هو الأي يعطي قيمة لرأس المال المادي والموارد الطبيعية ، وبدون العنصر البشري لن يكون للموارد الطبيعية اي قيمة. وذلك لأن البشر هم القادرون على استخدام هذه الموارد وتسخيرها في العمليات الإنتاجية للحصول على أقصى إثباع ممكن وصولاً إلى تحقيق الرفاهية ،

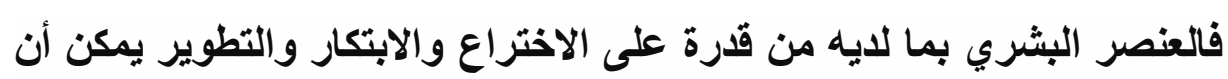
يتظلب علي ندرة الموارد الطبيعية ويوسع من إمكانيات المجتمع الإنتاجية.

والاهتمام بالعنصر البشرى يجعل الأفراد فى وضع يسمح لهم بتحقيق أهدافهم الشخصية والرضا الوظيفى وتحقيق الذات ، والفرد الذى يشعر بالرضا وتحقيق الأت يمكن أن يساهم بفعالية فى تحقيق الأهداف الاقتصادية بوجه عام وأهداف النمو الاحتوائى بوجه خاص، مما يؤثر على أداء الفرد وفعاليتهل'

فالدولة التي لا تهتم بتتمية مواردها البشرية لم ولن تستطيع أن تثقدم وتحقق غاياتها المرجوة، فالعقل والجهد البشري هو الأي يؤدي إلى التطور والتقدم ، فهو ضروري لتوفير رأس المال واستغلال الموارد الطبيعية استغلال أمثل هئل وخلق كل ما هو جديا وتلبية رغبات الاسواق والقيام بعمليات التبادل التجاري.

ولا جدوي من زيادة رأس المال المادي ما لم يصاحبه زيادة الخبرات والمعرفة بنفس المعدل على الأقل حتي تؤتي ثمارها، ولذا فإن افضل استثمار هو " للمزيد أنظر، راوية حسن، مدخل استراتيجى لتخطيطو تتمية المو ارد البشرية، الدار الجامعية،9 .. ب، 
الاستثمار في الموارد البثرية ، إذ أن الاستثمار الأمثل سيكون استثمار العقول والكفاءات البشرية خاصة في الدول النامية التي تحتاج بثدة إلى هذا النوع من الاستثمار حتى يمكنها استخدام مواردها المتاحة بأقصى كفاءة اقتصادية ممكنة، والاكتفاء الأتي بالخبراء المحليين بلأ من الاستعانة بالخبراء الأجانب للمساعدة في تثغيل أحدث ما وصلت إليه اختراعات الدول المتقدمة.

والغلبة في عصرنا الحالي للإنسان القوي نشأةًَ وتعليماً وتأهيلاً وتدريباً الذي يستطيع من خلال قدرته وكفاءته التظلب على معوقات التنمية التي تواجهه، ولذا يجب التركيز علي تطوير مختلف جوانب التنمية البشرية ألا وهي التعليم والتدريب من جهة والصحة من جهة أخرى، ومدى تطويرهما بما يتناسب ومتطلبات العصر. والدول المتقدمة أدركت مبكرا هذه الحقيقة في نهضنها العلمية والعملية، فوجهت معظم استثماراتها نحو تثمية العنصر البشري، وهدفت من وراء ذلك إلى رفع الكفاعة الإنتاجية وتميز هذه الثروة البشرية، وق حققت هدفها، والواقع خير دليل على ذلك.

وإن كان تقلم الولايات المتحدة، وبريطانيا، وفرنسا - وهم الدول المنتصرة في الحرب العالمية الثانية ـ طبيعياً، فإن من غير الطبيعي أن نجد من بين الدول المتقدمة ألمانيا، واليابان وهما الدولتان الخاسرتان في الحرب! وهما خير نموذج للاهتمام بالاستثمار في تنمية الموارد البشرية، وخاصةً اليابان، التي

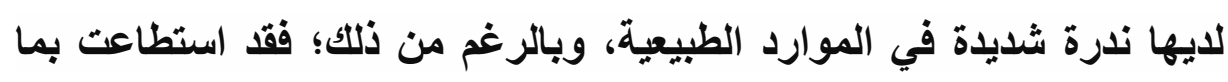
تمتلكه من ثروة بشرية أن تبني اقتصاداً قوياً، تقف من خلاله بين مصاف كبرة مبار

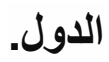

ولاللك نجد أهتمام نظريات رأس المال البثرى بقضية الاستثمار التعليمى، وتحليل مدخلات ومخرجات العملية التعليمية، وقد استفادت دول كثيرة من 
خلال الاسترشاد بمضمون نظرية رأس المال البشرى، لتنمية القدرة على

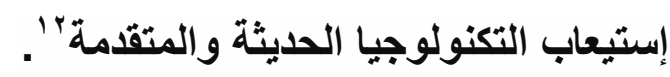

وها هي اليابان خير شاهد على نجاح الاستثمار، ونري الصين ايضا - صاحبة المليار ونصف المليار من البشر - تخطو بخطى ثابتة ومدروسة نحو قيادة

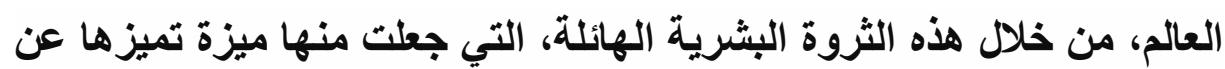

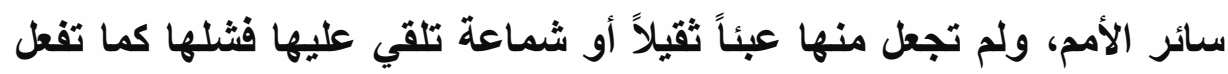
كثير من حكومات العالم الثالث.

فالموارد الطبيعية والأموال المادية المتوافرة لاولة ما - رغم أهميتهما وضرورتهما الكبرى - إلا أنهما لا يغنيان أبداً عن العنصر البشري الواعي

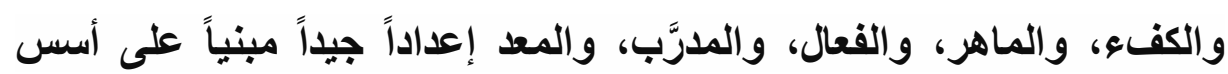
علمية دقيقة، وهذه حقيقة راسخة على مر العصور والأزمان، فالأموال والموارد الطبيعية لا ينتجان منتجاً بذاتهما، فالبشر - بخصائصهم التي خلقهم الله - سبحانه وتعالى - عليها - هم القادرون على استخدام هذه الموارد بنسب متفاوتة من حيث الكفاءة والفعالية ـ في العمليات الإنتاجية، للحصول السلع والخدمات التي تعمل على تحقيق أقصى إثباع ممكن للحاجات الفسيولوجية للفرد، بهدف الوصول إلى تحقيق الرفاهية أو الحياة الكريمة للفرد والمجتمع؛ ومن ثََّّ التقدم الاقتصادي للاولة،، وللاقتصاد العالمي ككل.

\section{r- ضعف الاستثمار ضات الاجنبية}

يعتبر الاستقرار الاثتصادي عاملاً حاسماً ومهما لاستقطاب المستثمر الأجنبي الذي يدعم النمو الاحتوائى، ومنع هروب رؤوس الأموال الوطنية إلى الخارج. إذ أن المستثمر يسعى أساساً من وراء استغلال أمواله r' للمزيد، أنظر عبداله محمد عبدالرحمن ، علم الاجتماع، النشأة والنظور، دار المعرفة الجامعية، الاسكندرية

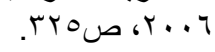


ووحداته الإتتاجية إلى تحقيق عوائد مجزية. ولن يتسنى لله ذلك إلا إذا كان اقتصاد الدولة التي يستثمر فيها مستقراً، لا تعصف به الأزمات إلهات الاقتصادية، بحيث يمكنه التببؤ بالمخاطر الاقتصادية، التي تعترض له نشاطه، لكي يستطيع التأمين منها وتجنب آثارها السلبية. ويظهر عدم الاستثرار الاقتصادي الأي يمكن أن يعوق الاستثمار في حالات من أهمها

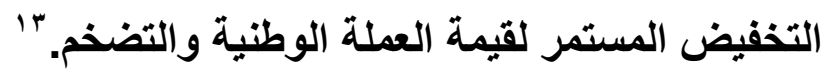

\section{ع- عدم وضوح استر اتيجية السياسة المالية والسياسة النقدية}

تحتل السياستان المالية والنقدية مكانة هامة نظرا لأهميتهما فى تحقيق الأهداف الاقتصادية المتعددة، وعلى رأسها النمو الاحتوائى، حيث تعد أدوات هاتين السياستين من أهم الادوات الاقتصادية التي يستعان بها لبلوغ هدف التنمية الاقتصادية بشكل عام ، والنمو الاحتوائى بشكل خاص، كما تستخدم أدوات هاتين السياستين في القضاء على المشاكل التي تعيق الاستقرار

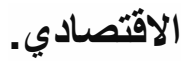

حيث يلعب الانفاق الحكومي والايرادات الضريبية من جهة، وأدوات السياسة النقدية كسعر الخصم والاحتياطي النقدي من ناحية أخري، أدوارا هامة من خلال التأثير علي الطلب الكلي والعرض الكلي ومن ثم التأثير علي المتغيرات الاقتصادية الكلية تلبية لمتطلبات التنمية الاقتصادية بثكل عام ، ويما يخدم النمو الاحتوائى بثكل خاص. 
وتعد مصر إحدي الدول النامية التي تعاني من عدم وضوح واستثرار السياستين المالية والنقية خاصة بعد الازمات الامنية والسياسية التى مرت

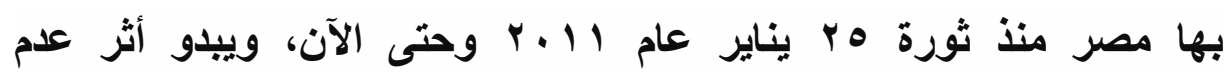
الاستثرار واضحا جليا فى العجز المستمر لميزان المدفوعات ، وارتفاع معدل البطالة والتضخم، لذا من المحتم التنسيق المستمر بين السياستين المالية والنقدية ، لضمان تحقيق التوازن الاقتصادي الاخلى والخارجي.

فالسياسة المالية هي مجموعة الأدوات التي تستخدمها الدولة للتأثير على النشاط الاقتصادي لتحقيق هدف معين من خلال الحوافز الضريبية وتخفيض الضرائب؛'، والتى تعمل على تثجيع الاستثمار من ناحية وتنشبط الاستهلاك وزيادة الانتاج من ناحية أخرى ، وكأن الدولة تتنازل عن جزء من حقها لصالح المستهلكين '، وتتكون هذه الأدوات من أدوات الإنفاق العام، وأدوات الإيرادات العامة، التي تلعب دورا هاما في تحقيق التوازن الاقتصادى، من خلال التأثير على مستوى التوظيف والادخار والانتاج والاستهلاك ، بما يحقق أهداف النمو الاحتوائى '17

فالضرائب مثلا لم تعد أداة لتمويل الايرادات العامة بل أصبحت أداة هامة ذات تأثيرات إقتصادية وإجتماعية تستهدف تحقيق خطط التمية الاقتصادية، لاسيما خطط وبرامج وأهداف النمو الاحتوائى.

؛' للمزيد، أنظر د/السيد عطية عبد الواحد ، الاتجاهات الحديثة في العلاقة بين السياسة المالية و النقدية، دار

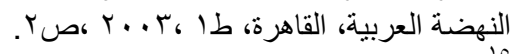
Leopold von Thadden, "Active Monetary Policy, Passive Fiscal Policy and the Value of Public Debt: Some Further Monetarist Arithmetic", Economic Research Centre of the Deutsche Bundesbank, Discussion Paper12/03, June2003, p. 65 Mello, Luiz de, Monetary Policies and Inflation Targeting in Emerging Economies

(OECD, 2008), P 25. 


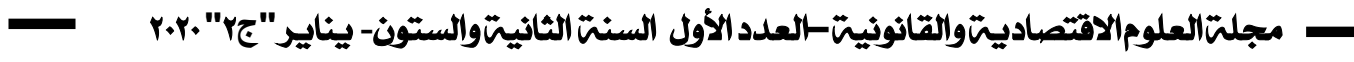

كما ينبغي الاشارة إلي دور وأهمية السياسة النقدية والتى تعتبر بمثاية المكمل والمتمم للسياسة المالية، حيث لا يتصور للسياسة المالية أن تحقى أهدافها الاقتصادية والاجتماعية دون التنسيق المحكم بينها وبين السياسة النقدية. ويقصد بالسياسة النقدية كافة الوسائل التي تمتلكها السلطات النقدية في الدولة بهدف إحداث أثار محددة في كمية النقود المتاولة، فهي تتمثل فى مجموعة الاجراءات التى تتخذها الدولة لإدارة النقا والائتمان وتنظيم السيولة العامة

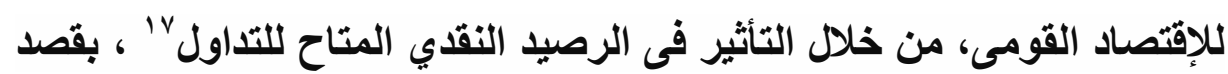
إحداث حالة التوسع أو الانكماش المتعمد تلبية لمتطلبات النمو الاحتوائى.

فالسياسة النقدية تمثل إستراتيجية مثلى تتنهجها السلطات النقدية فى الدولة بهدف توجيه النشاط الاقتصادى نحو تحقيق النمو الاحتوائى المتوازن والمستدام، وزيادة الناتج القومى بالقدر اللازم للوصول إلى حالة الاستقرار النسبى للأسعار المحلية، سواء أسعار السلع والخدمات أو أسعار صرف العملة الوطنية، وذللك من خلال مجموعة القوانين والاجراءات التى يمكن للسلطات

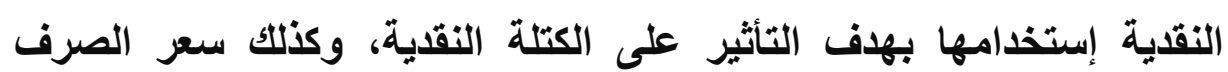
لضمان مرونة الجهاز الانتاجى مع المحافظة على رصيد الدولة من العملات

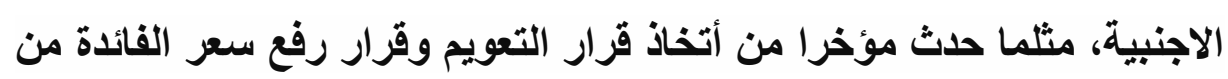

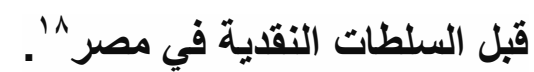

Sause, Gorge, Banking and economic activity, D. c health and company, New York '' , 1960, p197.

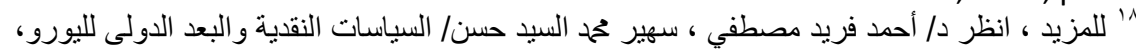

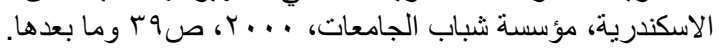




\section{المبحث الثالث}

\section{كيفية دعم السياسة المالية للنمو الاحتو ائى}

قبل محاولة رسم السياسات الاقتصادية والمالية التي تخدم النمو الاحتوائي بثكل عام، ينبفي أولا التعرف علي أهم العوامل التي تساعد علي زيادة وجودة انتاجية العوامل المساهمة في الانتاج، حتى يمكنتا الوصول إلى نمو مستدام ومتواصل وحقيقي مدعم بزيادة حقيقية في الناتج المحلي، فالتعرف علي العوامل المحددة والمؤثرة في زيادة انتاجية عوامل الاتتاج يعتبر بمثابة نقطة البداية لتحسين وزيادة معدل النمو الاحتوائي والناتج الاجمالي بشكل عام، ومن أهم

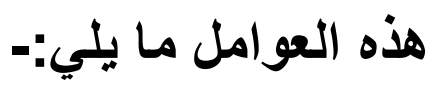

\section{1- الاستثمار في رأس المال البشري}

ثروة المجتمع الحقيقية تكمن أساساً في قرات مواطنيه ومدى إدراكهم وقدراتهم العلمية والتكنولوجية، الأمر الذي يدفع المجتمع إلى وضع مسألة تنمية العنصر البشري في

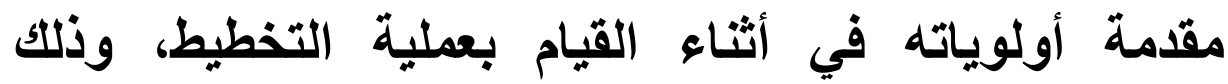
باعتبارها من أهم العوامل التي تساهم في الإسراع بعملية 
التتمية الاقتصادية الشاملة، فالعنصر البشري يمثل شرطاً أساسياً لتحقيق التتمية الثاملة.

ويقصد بالاستثمار في رأس المال البشري، مدى اهتمام الدولة بالاستثمار في تنمية وتطوير العنصر البشري من خلال التعليم. وبالطبع فمن المتقق عليه أن التعليم بعتبر واحداً من أهم مصادر زيادة خبرات ومهارات الأفراد، والتي بدورها تعمل على زيادة كفاوتهم الإنتاجية. ومن ثم فمن المفترض نظرياً أنه كلما زاد المستوى التعليمي كلما زادت الكفاعة الإنتاجية.

ونلاحظ أن العنصر البشري بما ميزه الله - سبحانه ـ من عقل وطاقات وجه بشري يمثل أهم عنصر من عناصر الإنتاج، وهذا التضافر يؤدي بلا ريب إلى بـ

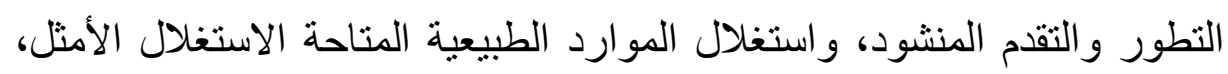
وفتح الأسواق، والقيام بعمليات التبادل التجاري... إلخ، فهناك دول تمتلك موارد بسيطة، ومع ذلك فهي دول متطورة،. ومما لا شك فيه أن الدولة التي لا تسنطيع ـ أو تعجز عن - تنمية مواردها البشرية لا يمكنها أن تحقق غاياتها وأهدافها المخططة والمأمولة، مهما ابتكرت من وسائل، و إنما يمكنها أن تحقق غواياتها وأهدافها عن طريق تضافر جميع عناصر الإنتاج: (الأرض، و العمل، ورأس والثان

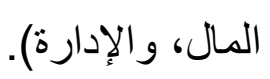

ونستطيع استنتاج العلاقة الطردية بين تنمية العنصر البشري والإتتاجية والمساهمة في القيمة المضافة. حيث أنه كلما زادت إنتاجية الفرد؛ زادت 
مساهمته في القيمة المضافة إلى المنتج النهائي، فضلاً عن زيادة أهمية دوره الوظيفي، مما ينعكس على شعوره بمدى أهميته في مكان عمله، وما يحصل عليه من مزايا معنوية، متمثلة في شهادة تقدير، أو ثناء رؤسائه على عمله وتقديرهم لله، مما يزيد من روحه المعنوية، التي تدفعه إلى بذل المزيد من هن

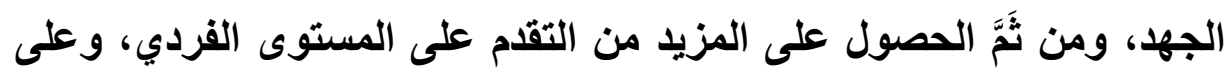
مستوى العمل، ومن ثََّّ شعوره بمدى أهميته داخل مجتمعله وعدم التفكير في الهجرة، فضلاً عن المزايا المادية، المتمثلة في زيادة الدخل، والمزايا العينية الأخرى.

وعلى النقيض من ذلك، كلما انخفضت إنتاجية الفرد؛ انخفضت - وقد تتلاشى ـ مساهمته في القيمة المضافة إلى المنتج النهائي، فضلاً عن انخفاض أهمية دوره الوظيفي، مما ينعكس على شعوره بمدى عدم أهميته في مكان عمله ـ والذي قد يتعرض لفقده - وما يترتب على ذلك من آثار نفسية سلبية ومؤلمة، تؤدي بلا شك إلى المزيد من انخفاض الروح المعنوية، فضلاً عن العقوبات المادية التي قد يتعرض لها، من خصومات تؤدي في النهاية إلى انخفاض دخله، ومن ثََّّ شعوره بمدى عدم أهميته داخل مجتمعه.

ويجب ان اذكر بأن زيادة الإتتاجية لا تأتي فقط نتيجة كفاءة الإدارة في استخدام الأساليب الإدارية الحديثة في إدارتها للعملية الإنتاجية؛ بل يتواكب مع ذلك استخدام التكنولوجيا المتطورة والحديثة في تطوير المنتج بشكل مستمر، فضلاً عن الاستثمار في تتمية الموارد البشرية، وتطويرها المستمر، عن طريق وضع البرامج التدريبية المدروسة على أسس علمية؛ للنهوض الدائم والمستمر بالقوى العاملة المتاحة للشركة أو المنظمة، وحرص الإدارة الدؤوب على جودة المنتج وتميُزه، وهذا يتطلَب التخطيط السليم، والمتابعة المستمرة

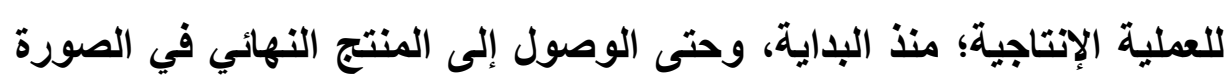


المرجوَة، ويتطلب ذلك من الإدارة أن تكون حريصة على كفاءة الخامات

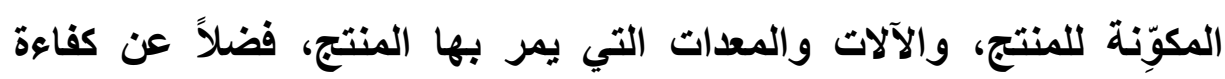
العمالة الماهرة التي تقوم بالعملية الإتتاجية.

و النمو الاقتصادي الاحتوائي هو الوسيلة لتحقيق التنمية البشرية ، فقد أظهرت

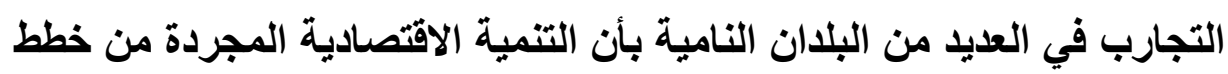

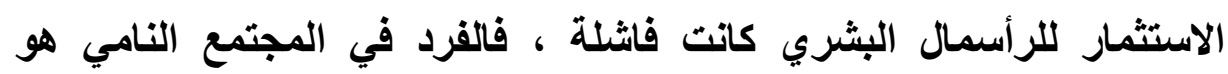

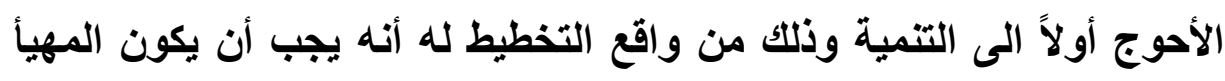

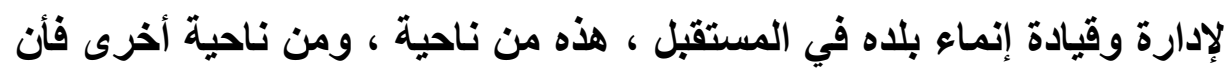

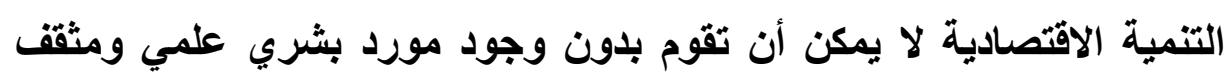

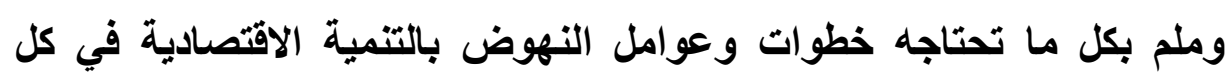

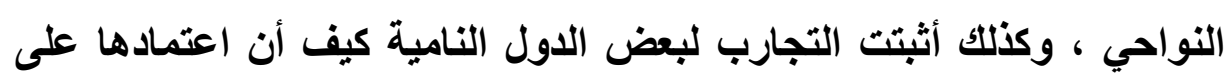

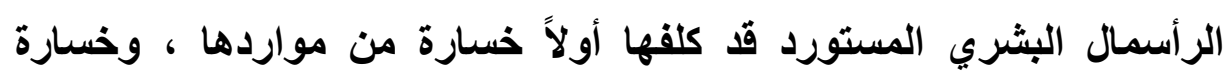

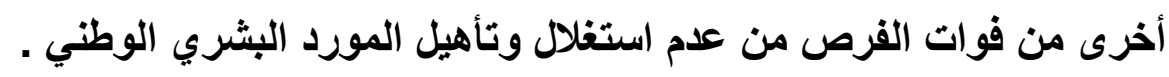

هذه العلاقة و هذه الأسس قد تتبه لها المخططون في الدول المتقدمة فهيأوا لها

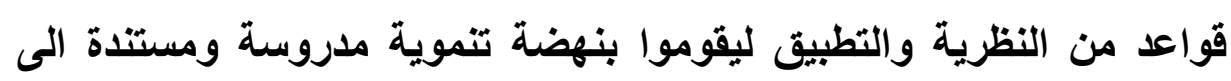

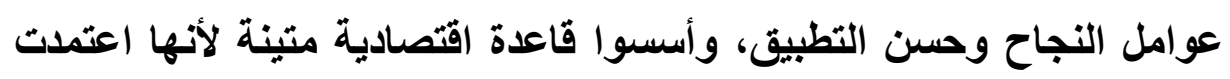

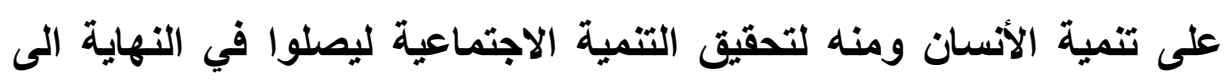

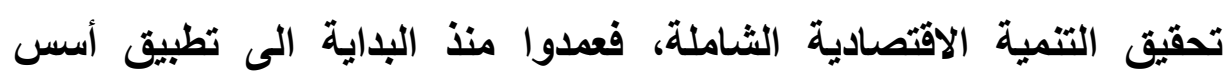

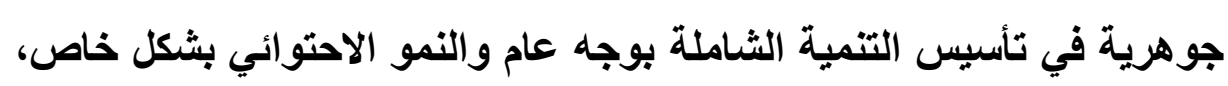

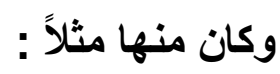

أ - إن الثروة لوحدها لا تعني التنمية بل يجب تعبئة الطاقات الاجتماعية

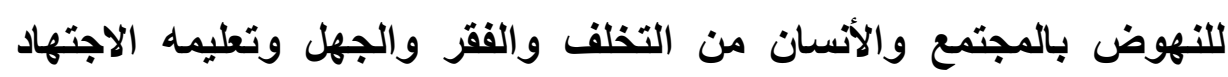
ليكون عنصرا فعالا بالمجتمع ويثارك في بناء اقتصاد بلدان. 
ب - يجب الاهتمام بتوجيه الرعاية التعليمية والتقنية للسكان وتطوير مهاراتهم ليكونوا فاعلين في مسيرة التنمية، لكي تعتمد عليهم في تطبيقها واستثمار الموارد الطبيعية المتوفرة دونما حاجة للطاقات الأجنبية.

ج- إن التنمية الاقتصادية الحقيقية تتجلى في تأسيس واقع بشري تنموي ذو قرات خلاقة تتناسب وحاجة البلا للتطور والرقي في كافة المجالات ومواجهة التطورات في الاقتصاد العالمي .

د - إن التنمية لا تكمن في إنشاء المصانع والمؤسسات وتوسيع الأنشطة التجارية بعيداً عن شمول الأنسان نفسه أولاً بهذه التنمية.

ه - ان هجرة العقول المصرية إلى الخارج عائقا أمام تطوير رأس المال البشرى؛ حيث تهاجر أفضل العقول إلى أوروبا والولايات المتحدة التى تثميز بييئات نظم التعليم العالى والبحث العلمى المواتية للابتكارج"، وتوفر تمويلا أكبر للبحث، وتتمتع ببنية تحتية قوية، وتوفر أجورا أفضل، وتتعاون بشكل

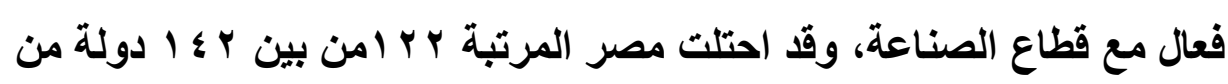

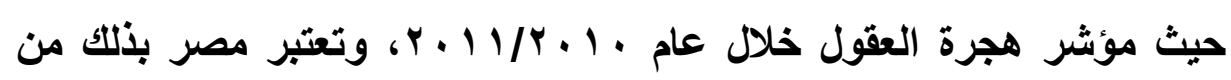

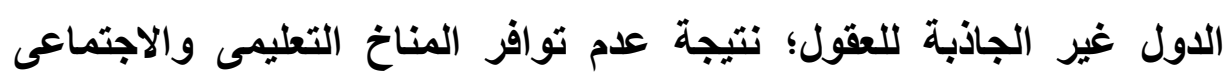
والاقتصادى والانفلات السياسى.

9 آيات صلاح دكرورى، دور اقتصاد المعرفة فى تحديث الصناعة ، دراسة تحليلية بالتطبيق

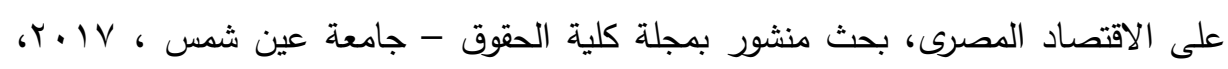

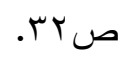


وليس ببعيد عنا تجربة الصين وماليزيا مثلاً عندما وصلا للنجاح والتقدم في المسيرة التنموية الاقتصادية من خلال اعتمادهما على مبدأ الاستثمار الاجتماعي الأتي والأي قادهما نحو نجاح التنمية الثاملة.

\section{r - الاستثمار ات الأجنبية المباشرة}

يلاحظ أن تدفق الاستثمارات الأجنبية قد يجلب معه عمالة فنية مدربة تساهم

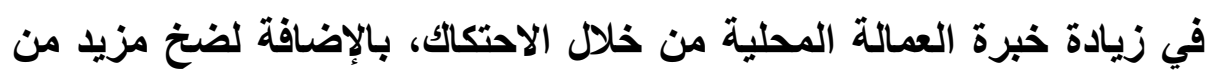
التكنولوجيا الحديثة ، سواء في شكل ملموس مثل الآلات والمعدات، أو شكل هن من غير ملموس مثل الأفكار الجديدة ونظم العمل الحديثة ـ- بالإضافة للمهارات الإدارية التي يمتلكها العنصر البشرى ومن ثم فإنه يتوقع وجود علاقة طردية بين تافق الاستثمارات الأجنبية المباشرة ومجمل إنتاجية عوامل الإنتاج . ويتم استخدام نسبة الاستثمارات الأجنبية المباشرة للناتج المحلي الإجمالي

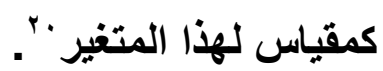

ولكن يجب الحذر من الاعتماد على الاستثمارات الأجنبية المباشرة بشكل أساسي اعتمادا كليا، حيث شهد التاريخ العواقب الوخيمة للنظرة الضيقة للتنمية الاقتصادية لبعض الدول العربية المالكة للثروات النفطية التي تصورت أن التنمية هي امتلاك الثروة فحسب ، فعددت الى استثمار الموارد الاقتصادية من خلال جلب الثركات الأجنبية وأسست واقعا صناعيا أجنبيا داخلها وأضحت التنمية تعني لها تطوير البنى التحتية دون التخطيط لتهيئة أفراد المجتمع نفسه للمشاركة في الاستثمار الاقتصادي القائم، وبذلك أصبح الاستثمار الأجنبي هو المستفيد الأكبر من هذه التنمية وأفراد المجتمع عبارة عن مستهلكين. 
إن الفشل في تطبيق التنمية الاقتصادية في البلدان النامية كان نتيجة اقتصار

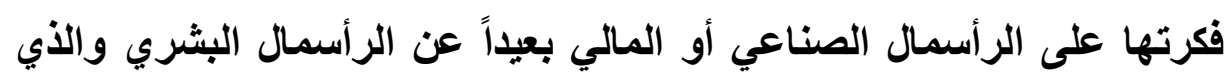
هو أساس تقدم المجتمع الاقتصادي.

\section{ب- درجة الانفتاح الاقتصادي للدول}

لاشك في أن الانفتاح الاقتصادي المدروس وبما يتناسب مع اقتصاد وموارد البلا ، يجلب التكنولوجيا الحديثة بما يعمل على زيادة انتاجية عوامل الانتاج وبالتالي خدمة النمو الاحتوائي بطريق غير مباثر. فالعلاقة طردية إذن بين الانفتاح الاقتصادي وزيادة الكفاءة الانتاجية، أي أنه كلما زادت درجة انفتاح الدولة اقتصادياً على العالم الخارجي، كلما ساعد ذلك على حصول الدولة على الثى تكنولوجيا أعلى، ومسايرتها للتقنيات الحديثة في مجال الإتتاج مما يؤدي لزيادة الكفاءة الإنتاجية وبناء عليه، فمن المتوقع وجود علاقة طردية بين درجة

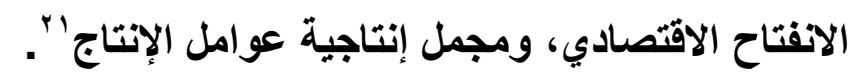

\section{ع- جودة الحكومة}

مما لا شك فيه وجود علاقة طردية بين مدى جودة الحكومة وبين مجمل إنتاجية عوامل الإنتاج، حيث أن خلق مناخ عمل جيذ وفعال، واحترام الدولة للقوانين، وتثجيعها للاختراعات الحديثة، وحماية الملكية الفكرية، كلها عوامل مهمة تساهم وبشكل مؤثر وفعال في إيجاد الحافز لاى الأفراد

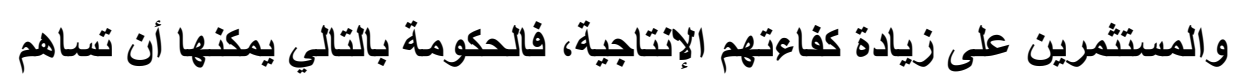

بشكل فعال في زيادة الكفاعة الإنتاجية.

Fischer, S., (1993), "The Role of Macroeconomic Factors in Growth", Journal of ${ }^{r}$ Monetary Economics, 32, pp, 485-512. 
وفي المقابل ستكون العلاقة عكسية بين البيروقراطية الحكومية حيث التأخير

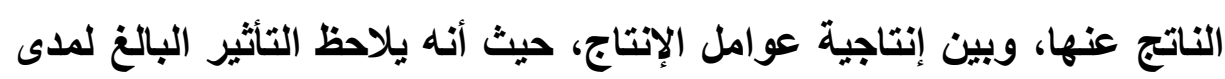
احترام الحكومة بتنفيذ العقود والتعهدات في مجال الأعمال، ومدى توافر نظام قانوني وسياسي يحترم حقوق المستثمرين والأفراد علي كفاءة وانتاجية عوامل الانتاج، كما أنه من المؤكد أن توافر مثل تلك المتغيرات سيعمل على وفي ولى

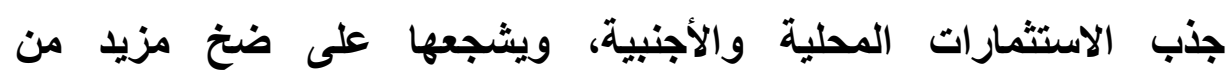
التكنولوجيا داخل البلاد.

\section{هـ المتغيرات الاقتصسادية الكلية و هيكل الواردات السلعية}

إن وجود استقرار وثبات نسبي في متغيرات الاقتصاد الكلي يعتبر من العوامل المشجعة على جذب الاستثمارات والتي بلورها ستعمل على إدخال تكنولوجيا حديثة ومتقدمة للمجتمع. ومن ثم فمن الملاحظ وجود علاقة طردية بين درجة الاستقرار في متغيرات الاقتصاد الكلي والكفاءة الإنتاجية.

كما يلاحظ أيضا وجود علاقة طردية بين نسبة الاستيراد من الآلات والمعدات لإجمالي الواردات وبين زيادة إنتاجية عوامل الإنتاج، حيث يفترض أنه كلما احتلت الآلات والمعدات نسبة أكبر في هيكل الواردات السلعية ككل، كلما كان ذلك مؤشراً على توجه الدولة لتحديث صناعتها وجذب تكنولوجيا جديدة مما يزيد من احتمالية زيادة إنتاجية عوامل الإنتاج ورفع الكفاعة الإتتاجية. 


\section{الخاتمة}

وفي النهاية يجب التاكيد على حتمية تبنى حزمة الإصلاحات التى تنظوى على منهج شامل يضمن تحقيق عدد من الأهداف التنموية الهامة، كالنمو الإحتوائى والأنصاف الإجتماعي من جهة وبين زيادئ الإيرادات الحكومية من جهة أخرى.

وهنا يأتى دورالبرامج الإجتماعية الموجهة بعناية إلى المستحقين الفعيين والمهمشين فى المجتمع لضمان العدالة وتحسين الرفاهية، والتى تعمل على القضاء على التثوهات الإقتصادية، وتخفيف الأثار التوزيعية السلبية، والدد من عدم المساواة، وكذلك ضمان توزيع التصائ

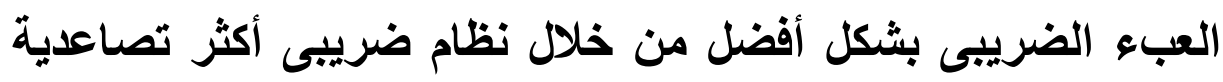
يكفل تحقيق العدالة بين المموليين فى تحمل أعباء النمو الإحتوائى.

وإذا حاولنا ضرب مثّلا توضحيا، فإن زيادة فرض ضريبة على

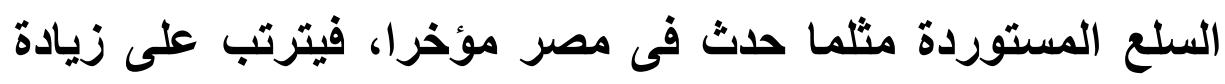
الضرائب على السلع المستوردة أن المستهلكين يحولون إستهلاكهم

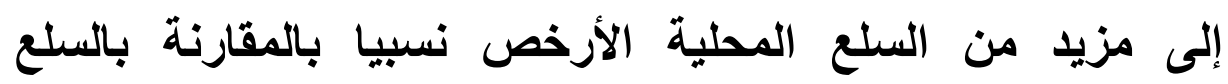

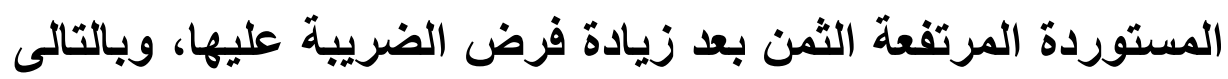

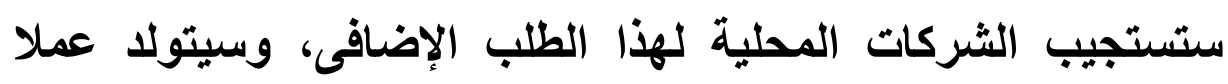

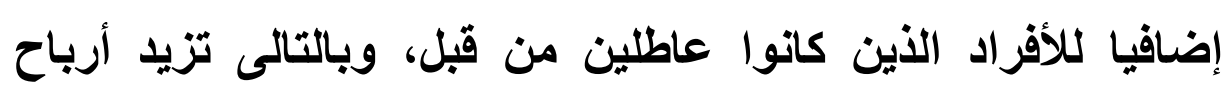


أصحاب المشاريع وتتخفض البطالة تدريجيا، ويرتفع الناتج المحلى بشكل عام، وكل ذلك يصب فى مصلحة النمو المستمر والإحتوائى.

بينما إذا بالغت الدولة فى زيادة فرض الضرائب على السلع المحلية، فسيؤدى ذلك إلى تقليل الإستهلاك نتيجة إنخفاض القوة الشرائية لما يمتلكون من نقود ، وبالتالى سينخفض الطلب الكلى، الذى سيترتب عليه إنخفاض أرباح الثركات المحلية مع إستمرار تزايد معدل البطالة ويصبح العاملون أكثر فقرا. وهنا يبرز دور شبكة الأمان الإجتماعى التى تحاول علاج الأثنار السيئة لزيادة فرض الضرائب المولا للفقراء، ولكن على حساب إنخفاض الإيرادات العامة.

وهنا تكمن صعوبة المفاضلة بين زيادة الإيرادات العامة على حساب الفقزاء إعثمادا على شبكة الأمان الإجتماعى، التى يجب أن توجه بدقة إلى المستحقين الفعلين لمحاولة التخفيف من بعض الآثار السلبية التي تقع على العاملين نتيجة فقدان الإمتيازات الضريبية ، وبين تحسين الرفاهية الإقتصادية بشكل عام على حساب ضعف الإير اداث العامة.

وللخروج من هذا المأذق فينبخى تبنى حزمة من الإصلاحات الإقتصادية والمالية الشاملة ، لتحقق نتائج أفضل. ولهذه الإصلاحات جناحين ينبغى العمل على توازنهما بشكل مستمر، أولهما زيادة 


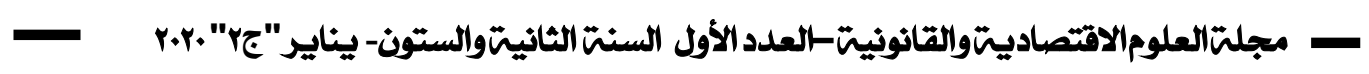

معدلات الضرائب والحد من الإعفاءات الضريبية، وثانيهما العمل

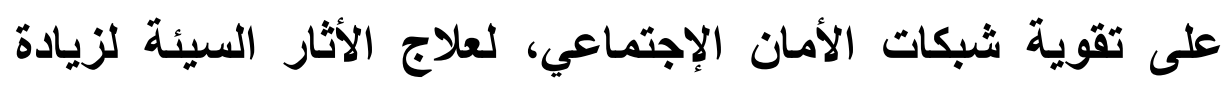
فرض الضرائب لما ذكر أنفا.

\section{نتائج البحث}

من خلال ما سبق ينتهي الباحث الى مجموعة من النتائج الهامة ، والتى يمكن أيجازها فى النقاط التالية:-

1- النمو الاحتوائى يهدف الى جودة الانتاج والمشاركة الاجتماعية وعدالة التوزيع.

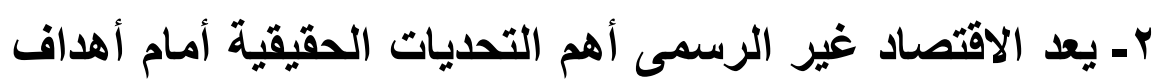

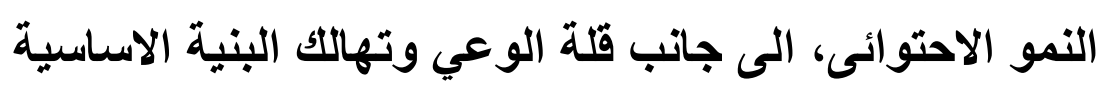
وضعف الاستثمار.

r- ينبغى التنسيق التام بين السياستين المالية والنقدية لتجنب الأثار غير المرغوبة نتيجة الاعتماد على إحداهما وتجاهل الاخرى.

ع - يجب الحذر من الاعتماد على الاستثمارات الأجنبية المباشرة بشكل أساسي اعتمادا كليا. هـ لوحظ أن الفشل في تطبيق التنمية الاقتصادية في البلان

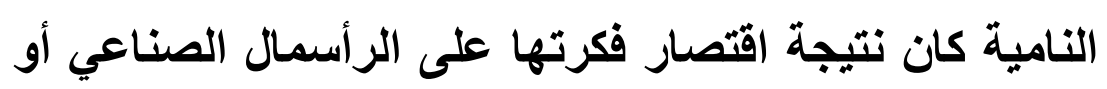
المالي بعيداً عن الرأسمال البشري. 
7- توجد علاقة عكسية بين البيروقراطية الحكومية حيث التأخير الناتج عنها، وبين إنتاجية عوامل الإنتاج.

V- بينما العلاقة تكون طردية بين درجة الاستقزار في متغيرات الاقتصاد الكلي والكفاءة الإنتاجية.

\section{الثبوصباثب}

يتضح مما سبق أن المشكلات الاقتصادية التي يعانيها المجتمع المصري ، لم تكن وليدة اللحظة ، وانما كاتت نتيجة عدة تراكمات لمسارات خاطئة منذ عقود، الامر الأي يحتم تغيير المسار لاعم النمو الاحتوائي المستدام.

والمسار الصحيح يقتضي التعرف على عناصر الازمة الفعلية والحقيقية مع وضع حلول جادة للتظلب عليها ومعالجتها بحكمة، ويجب التنويه إلى أن علاج الإختلالات الاقتصادية مسئولية كل فرد علي أرض الوطن حكومة ومسئولين وأفراد عاديين، فينبغى على كل فرد تحمل المسئولية ، كما ينبغى على كل فرد إصلاح نفسه، ويمكن حصر متطلبات النمو الاحتوائي، التى من الواجب العمل ليلا ونهارا على تهيئة المناخ لتحقيقه فى الأتى:-

ا - حتمية اعادة تنظيم الضرائب إداريا، وإعادة توزيع الحصيلة الضريبية بحيث يشعر جميع دافعي الضرائب وغير دافعي الضرائب من الفقراء بعائد وثمار الحصيلة الضريبية، ولن 
يتأتي ذلك إلا بإعادة تظيم الضرائب بما يفسح المجال للامركزيه الضريبية على هسب التحصيل والتوزيع المركزي.

r ـ فمثلا ضرائب الصعيد ينبغى أن ينتفع منها أولا فقراء واغتياء الصعيد، أى تكون الحصيلة الأكبر لتتمية الخدمات والمرافق المحيطة بمن أستجابوا لتداء النمو الاحتوائى ، ودفعوا الضرائب المستحفة عليهم عن طيب خاطر بلا تهرب. r- إن تبني سياسة اللامركزية الضريبية علي الوجه المقترح أنفا، سيعمل على طمأنة البسطاء والفقراء ممن لا يملكون إلا قوت يومهم، واشعارهم بأن قضيتهم تؤرق المجتمع ككل ، وأن أصحاب القزار لن يهدأ لهم بال حتى يضمنوا لهم استقرارا اقتصاديا واجتماعيا من خلال دعم النمو الاحتوائى المستدام. عـ حتمية التسبيق بين السياستين المالية والتقدية، حيث لا يمكن تحقيق نمو أقتصادى إحتوائى حقيقى بدون التنسيق التام بينهما، كما لا يمكن تفضيل أحدي السياستين على الأخرى. فكلاهما على نفس المستوى والدرجة من الأهمية، ولا يمكن تفضيل إحدى السياستين على الاخرى، بل ينبغى التنسيق التام بينهما لضمان نجاح الأهداف الاقتصادية المرجوه، وبدون هذا التتسيق قد تهام السياسة النقدية هدفا بتته السياسة المالية ، أو العكس قد تهدم السياسة المالية هدفا بنته السياسة النقدية. 
هـ ضرورة العمل على توعية المواطنين بمخاطر زعزعة الامن والاستثرار السياسى والاقتصادي وما يترثب عليها من مخاطر إقتصادية سواء على المدى القصير أو على المدي البعيد، فضلا عن تعطيل مسيرة النمو الاحتوائى. 7- لابد من دعم وتثجيع المشروعات الصغيرة والمتوسطة والمتناهية الصغر، والتى تعد من أهم روافد التتمية الاقتصادية والنمو الاحتوائى على وجه التحديد، فالمشروعات الصغيرة والمتوسطة تؤدى إلى تغطية الاستفادة من الموارد البشرية المتاحة من خلال زيادة إنتاجيتها لصالح المجتمع ككل من جهة وتحسين جودة السلع والخدمات نتيجة المنافسة ما بين المشروعات الصغيرة وبعضها البعض أو بينها وبين المشروعات الكبيزة خاصة في الدول النامية، وذلك باعتبار ها منطلقاً أساسياً لزيادة الطاقة الاتتاجية من ناحية، والمساهمة في معالجة مشكلتي الفقر والبطالة من ناحية أخرى. ولذلاك أولث دول كثيرة هذه المشاريع اهتماماً متزايداً، وقدمت لها العون والمساعدة بمختلف السبل ووفقاً للإمكانيات المتاحة. V- ويأتي الاهتمام المتزايد بالمشروعات الصغيرة والمتوسطة، لقدرتها الكبيزة على استيعاب الأيدي العاملة ، بالاضافة لقلة حجم الاستثمار المطلوب فيها كثيراً بالمقارنة بالمشروعات الكبيرة ، فضلا عن قدرتها على تطوير المهارات الإدارية والقتية والإنتاجية والتسويقية، وتثجيعها على فتح مجالاً 


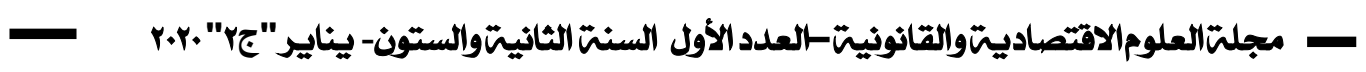

واسعاً أمام المبادرات الفردية والتوظيف الأاتي، مما يخفف

الضغط على القطاع العام في توفير فرص العمل.

1ـ تقديم التسهيلات المالية والائتمانية المختلفة لتنمية القطاعات

الحيوية والهامة في المجتمع ، وعلي رأسها قطاع السباحة

والمقاولات والتصدير وغيرها من القطاعات التى تساعد على

النهوض السريع بإقتصاد بلدنا الحبيب.

9- ضرورة محاربة الرشوة والفساد التى تفثت بين معدومى

الضميز، والعمل على إستئصال الفاسدين لتطهيز المجتمع

منهم، ولتهيئة المناخ للتمو الثامل والمستدام والاحتوائى. 


\section{قائمة المراجِ}

\section{أولا: باللغة العربية}

1- أحمد إبراهيم محمد متولى دهشان "التنسيق بين السياستين المالية

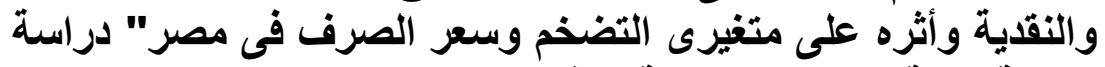

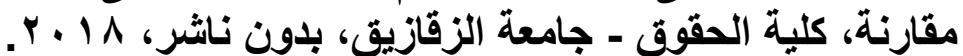

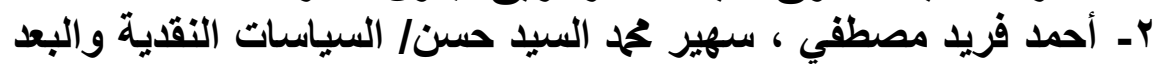

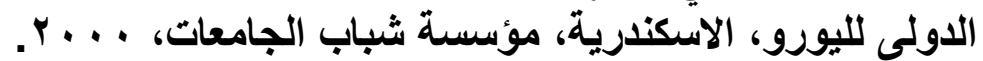

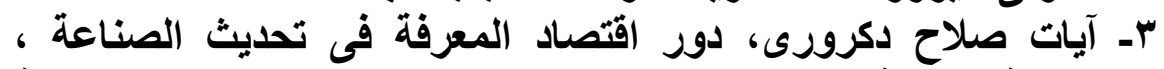

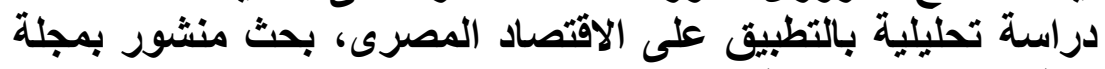

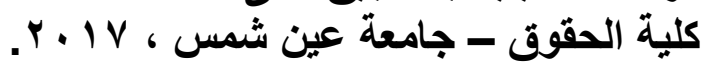

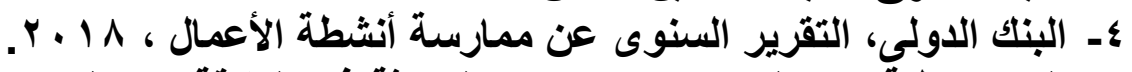

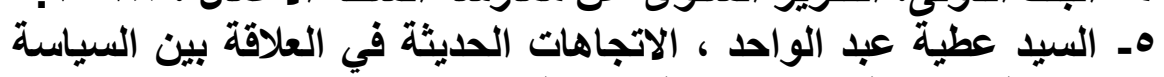

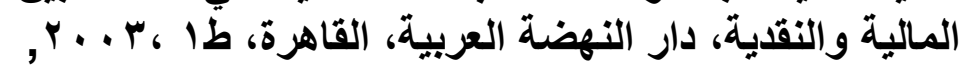

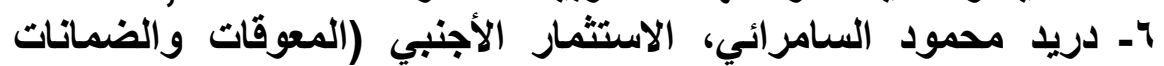

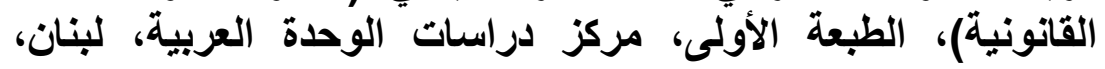

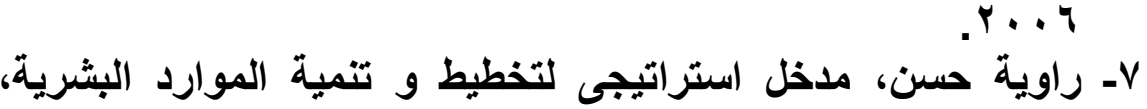

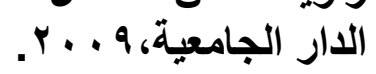

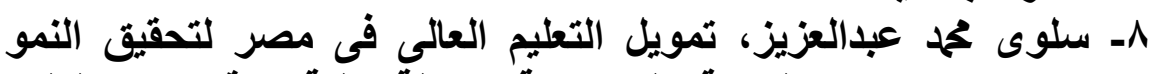

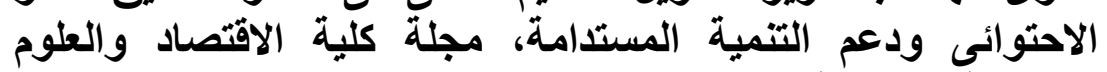

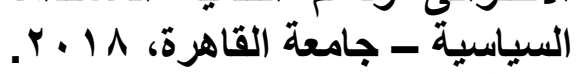

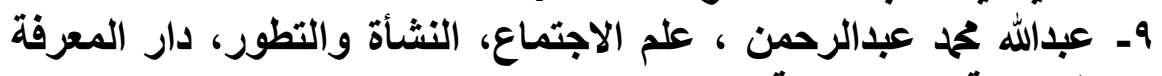

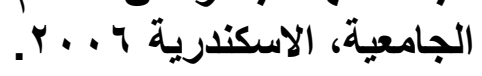
•

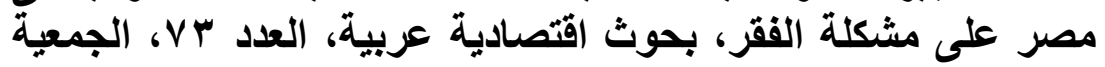

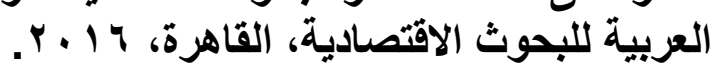

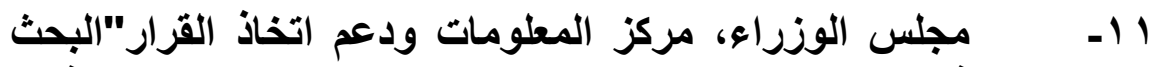

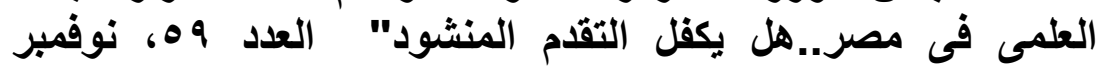

$$
\text { r. } 11
$$

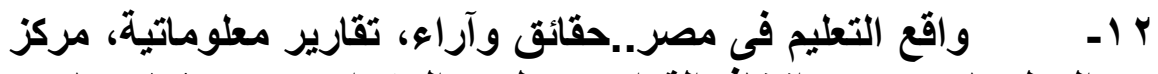

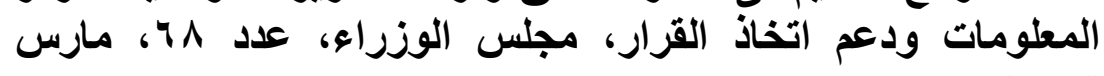
r 


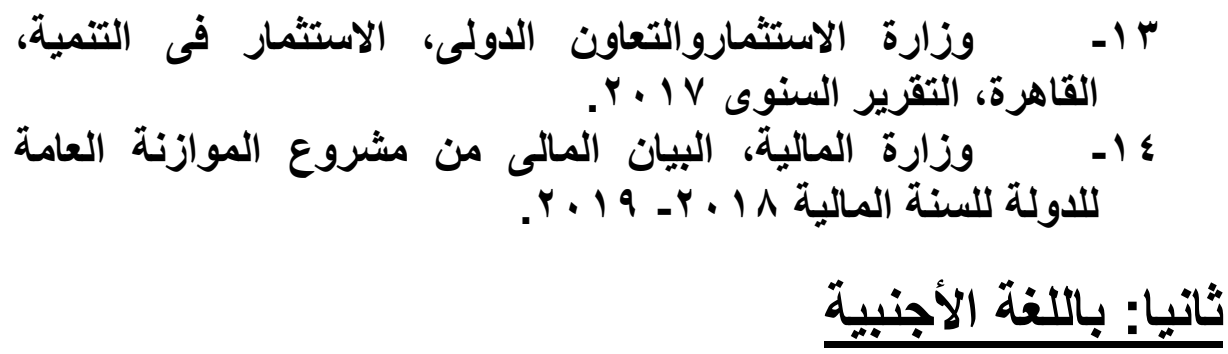

1. Adams, H., Page, J., (2002), "Holding the Line: poverty Reduction in the Middle East and North Africa, 1970-2000", Paper Presented at the 8th Annual Conference of the Economic Research Forum for the Arab Countries, Iran and Turkey, (Cairo: ERF, January 14-17).

2. Aghion, P., and Howitt, P., (1990), "A Model of Growth Through Creative Destruction", Econometrica, 60, 323-51.

3. Anonymous, (1990), "Egypt: It is a Long Road", Banker, 140 (773), 62-66. 7. Anonymous, (1996), "Egypt Facing the Modern World: Investment Jewel on the Nile", Euromoney, August, 11-13. 61

4. Bosworth, B., and Collins, S., (1998), Accounting for Economic Growth, (Washington, D.C.: Brookings Institute).

5. Central Bank of Egypt, (1998), Quarterly Economic Review, 32, (3).

6. Central Bank of Egypt, (1998), Quarterly Economic Review, 38, (4). 62 17. Central Bank of Egypt, Annual Economic Review, (Cairo: CBE, Various Issues, 1992-2001).

7. Chuang, Y. C., and Lin, C.M., (1999), "Foreign Direct Investment, RSD, and Spillover Efficiency: Evidence from Taiwan's Manufacturing Firms", Journal of Development Studies, 35 (4), 117-37.

8. Collins, S., and Bosworth, B., (1997), "Economic Growth in East Asia: Accumulation versus Assimilation", Brookings Papers in Economic Activity, (eds. William, C., and Perry, G.), 135-203.

9. Dhareshwar, A., and Nehru, V., (1994) "New Estimates of Total Factor Productivity Growth for Developing and Industrial Countries", Policy Research Working Paper No. 1313, (Washington, D.C.: IMF).

10. Djankov, S., and Hoekman, B., (2000), "Foreign Investment and Productivity Growth in Czech Enterprises", The World Bank Economic Review. 
11. Elias, V.J., (1992), Sources of Growth: A Study of Seven Latin American Countries, (San Francisco: ICS Press). 63

12. El-Safwa Brokerage Company, (1998), Capital Market In Egypt: History of Capital Market in Egypt, (Cairo: El-Safwa Brokerage Company).

13. Felipe, J., (1999), "total Factor Productivity Growth in East Asia: A Critical Survey", The Journal of Development Studies, 35 (4), 1-41.

14. Field, M., (1995), "The Slow Road to Privatization", Euromoney, Middle East Markets Supplement, November, 1213.

15. Fischer, S., (1993), "The Role of Macroeconomic Factors in Growth", Journal of Monetary Economics, 32, 485-512.

16. Handy, H. and Subrmanian, A., (1997), The Egyptian Stabilization Experience, (Washington, D.C.: International Monetary Fund, Middle East Department).

17. International Finance Corporation, (2001), Annual Report, (Washington, D.C.:, IFC). 64

18. International Finance Corporation, (2001), Emerging Market Data Base"EMDB", (Washington, D.C.: IFC)

19. International Monetary Fund, (1998), "Egypt, Beyond Stablization, Toward a Dynamic Market Economy", IMF Occasional Paper, (Washington, D.C.: IMF)

20. Martin, N. A., (1997), "International Trader: More Trouble could be in the Cards for Hong Kong's Jittery Stock Market", Barren's, 77 (39), 8-9.

21. McKinney, B. M., (1996), "Recent Development in Egyptian Investment Policies and Programs, and Pending Reform Legislation", Middle East Executive Reports, 19 (7), 9-12.

22. Ministry of Public Enterprise, (2002), Privatization Program Performance from the Start until June 2002, (Cairo:MPE).

23. Omran, M., (2002), "Detecting The Performance Consequences of Privatizing Egyptian State-Owned Enterprises: Does Ownership Structure Really Matter?", Paper Presented at the 8th Annual Conference of the Economic Research Forum for the Arab Countries, Iran and Turkey, (Cairo: ERF, January 14-17).

24. Omran, M., (2002), "Initial and Aftermarket Performance of Egyptian Share Issue Privatization" Working Paper. 


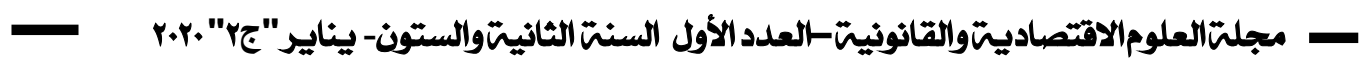

25. Pill, H., (1997), "Real Interest Rates and Growth: Improving on some Deflating Experience", Journal of Development Studies, 34 (1), 85-111.

26. Road, S., (1997), Investing in Egypt, (London: Committee for Middle East Trade).

27. Romer, D., (2001), Advanced Macroeconomics, (N.Y.: McGraw-Hill Companies, Inc. 2nd Edition).

28. Sala-i-Martin, X., (2002), "Sources of Growth", in Khan, M., Nsouli, S., and Wong, C., (ed.), Macroeconomic Management Programs and Policies, (Washington, D.C.: IMF)= 